\title{
Metastable ScAIN and YAIN Thin Films Grown by Reactive Magnetron Sputter Epitaxy
}

\author{
Agnè Žukauskaitè
}

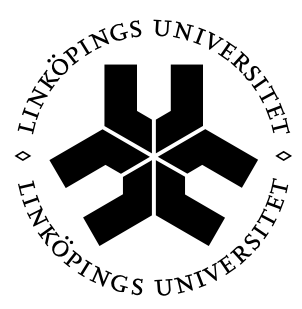

\section{Linköping University}

\section{INSTITUTE OF TECHNOLOGY}

Thin Film Physics Division

Department of Physics, Chemistry, and Biology (IFM)

Linköping University, Sweden

2014 


\section{The cover image}

The image on the cover is based on an elemental energy dispersive $\mathrm{x}$-ray spectroscopy map of $\mathrm{Sc}_{0.2} \mathrm{Al}_{0.8} \mathrm{~N}$ deposited at $400^{\circ} \mathrm{C}$ obtained in a transmission electron microscope. Each individual square represents an area of $\sim 1 \mathrm{x} 1 \mathrm{~nm}$. Here, scandium was assigned the green color, and aluminum is mapped using purple. No tendencies to cluster into Sc-rich or Al-rich regions can be seen, indicating a solid solution.

A special Thank You for recording this data goes to Dr. Justinas Pališaitis!

(c) Agnè Žukauskaitė

ISBN: 978-91-7519-434-9

ISSN: 0345-7524

Printed by LiU-Tryck

Linköping, Sweden, 2014 


\section{Abstract}

Metastable $\mathrm{Sc}_{\mathrm{x}} \mathrm{Al}_{1-\mathrm{x}} \mathrm{N}$ and $\mathrm{Y}_{\mathrm{x}} \mathrm{Al}_{1-\mathrm{x}} \mathrm{N}$ thin films were deposited in an ultra high vacuum system using reactive magnetron sputter epitaxy from elemental $\mathrm{Al}, \mathrm{Sc}$, and $\mathrm{Y}$ targets in $\mathrm{Ar} / \mathrm{N}_{2}$ gas mixture. Their structural, electrical, optical, mechanical, and piezoelectrical properties were investigated by using the transmission electron microscopy, x-ray diffraction, spectroscopic ellipsometry, I-V and C-V measurements, nanoindentation, and two different techniques for piezoelectric characterization: piezoresponse force microscopy and double beam interferometry.

Compared to AlN, improved electromechanical coupling and increase in piezoelectric response was found in $\mathrm{Sc}_{\mathrm{x}} \mathrm{Al}_{1-\mathrm{x}} \mathrm{N} / \mathrm{TiN} / \mathrm{Al}_{2} \mathrm{O}_{3}$ structures with Sc content up to $\mathrm{x}=0.2$. Decreasing the growth temperature down to $400{ }^{\circ} \mathrm{C}$ improved the microstructure and crystalline quality of the material. Microstructure of the films had a stronger influence on piezoelectric properties than the crystalline quality, which affected the leakage currents. When $\mathrm{x}$ was increased from $\mathrm{x}=0$ to $\mathrm{x}=0.3$, the hardness and reduced Young's modulus $\mathrm{E}_{\mathrm{r}}$ showed a decrease from $17 \mathrm{GPa}$ to $11 \mathrm{GPa}$, and $265 \mathrm{GPa}$ down to $224 \mathrm{GPa}$, respectively. In $\mathrm{Sc}_{\mathrm{x}} \mathrm{Al}_{1-\mathrm{x}} \mathrm{N} / \mathrm{In}_{\mathrm{y}} \mathrm{Al}_{1-\mathrm{y}} \mathrm{N}$ superlattices, $\mathrm{Sc}_{\mathrm{x}} \mathrm{Al}_{1-\mathrm{x}} \mathrm{N}$ layers negative lattice mismatched to $\mathrm{In}$-rich $\mathrm{In}_{\mathrm{y}} \mathrm{Al}_{1-\mathrm{y}} \mathrm{N}$ were found to be stable at higher Sc concentration $(x=0.4)$ than lattice-matched or positive lattice mismatched layers, confirmed by first principle ( $a b$ initio) calculations using density-functional formalism.

Al-rich $\mathrm{Y}_{\mathrm{x}} \mathrm{Al}_{1-\mathrm{x}} \mathrm{N}$ thin films were synthesized and reported for the first time. Formation of solid solution was observed up to $\mathrm{x}=0.22$ and an increase in growth temperature up to $900^{\circ} \mathrm{C}$ improved the crystalline quality of the $\mathrm{Y}_{\mathrm{x}} \mathrm{Al}_{1-\mathrm{x}} \mathrm{N}$ films. The band gap of $\mathrm{Y}_{\mathrm{x}} \mathrm{Al}_{1-\mathrm{x}} \mathrm{N}$ decreased from $6.2 \mathrm{eV}$ for $\mathrm{AlN}$ down to $4.5 \mathrm{eV}(\mathrm{x}=0.22)$ and was shown to follow Vegard's rule. Refractive indices and extinction coefficients were also determined. Lattice constants of wurtzite $\mathrm{Y}_{\mathrm{x}} \mathrm{Al}_{1-\mathrm{x}} \mathrm{N}$ measured experimentally are in good agreement with theoretical predictions obtained through $a b$ initio calculations. The mixing enthalpy for wurtzite, cubic, and layered hexagonal phases of the $\mathrm{Y}_{\mathrm{x}} \mathrm{Al}_{1-\mathrm{x}} \mathrm{N}$ system was also calculated. 


\section{Populärvetenskaplig sammanfattning}

Materialvetenskap är ett stort interdisciplinärt ämnesområde där kunskap från tillämpad fysik och kemi används för att få bättre insikt om materials egenskaper, för att skapa helt nya material, eller kända material i nya former, som nanostrukturer eller tunna skikt.

Tunna skikt finns runt omkring oss varje dag. Idén att använda tunna skikt för att ändra ytegenskaper är inte helt ny, men den hastiga tekniska utvecklingen under nitton- och tjugohundratalet har krävt nya avancerade lösningar och samtidigt givit oss nya verktyg att undersöka och modifiera omvärlden på atomnivå. Reaktiv magnetronsputtring är ett speciellt sätt att förånga material från ett fast material, vanligen en mycket ren metall. Atomerna i metallångan används sedan för att bygga upp nya beläggningar (tunna filmer) atomlager för atomlager. Denna process måste ske under ultra-lågt tryck, bland annat för att uppnå god materialkvalitet och undvika föroreningar i filmerna. En vanlig tillämpning av tunna filmer är som skyddande och dekorativa beläggningar, men det finns en annan grupp av tunnfilm som kallas funktionella tunnfilmer. Trycksensorer, lysdioder och många andra kommersiella produkter skulle inte kunna fungera utan någon typ av tunn beläggning. Aluminiumnitrid (AlN) är piezoelektriskt, dvs det genererar en elektrisk spänning då det deformeras mekaniskt, och ett bra exempel på ett funktionellt material. Det finns till exempel, en speciell elektronisk komponent (duplexern) i varje mobiltelefon som möjliggör samtidig sändning och mottagning av radiosignaler. Före 2001, var duplexern gjord av ett stort keramiskt block, men en ny teknologi baserat på geometriska strukturer och tunna filmer av aluminiumnitrid, så kallad TFBAR (Thin Film Bulk Acoustic wave Resonator) är mycket mindre, fungerar mycket bättre och möjliggör att fler abonnenter kan tala samtidigt i mobilnätet, och används därför uteslutande idag.

Aluminiumnitrids egenskaper är bra, men kan förbättras ännu mer genom att man blandar materialet med grundämnet skandium (Sc) och skapar legeringen 
skandium-aluminium-nitrid $\left(\mathrm{Sc}_{\mathrm{x}} \mathrm{Al}_{1-\mathrm{x}} \mathrm{N}\right)$. I denna avhandling visar jag, att den elektromekaniska kopplingen, dvs effektiviteten i omvandlingen mellan mekanisk och elektrisk energi, ökar från 7\% för ren $\mathrm{AlN}$ upp till 10\% i Sc $\mathrm{C}_{\mathrm{x}} \mathrm{Al}_{1-\mathrm{x}} \mathrm{N}$-tunnfilmer. Den piezoelektriska effekten är även starkare i det nya materialet. En utmaning med $\mathrm{Sc}_{x} \mathrm{Al}_{1-\mathrm{x}} \mathrm{N}$ är att i ren skandiumnitrid $(\mathrm{ScN})$ och $\mathrm{AlN}$ sitter atomerna ordnade $\mathrm{i}$ olika kristallstrukturer. I ScN sitter atomerna ordnade efter ett kubiskt mönster medan de i AlN sitter ordnade i så kallade wurtzit-struktur, en hexagonal ordning som påminner om staplade prismor. De har därför svårt att blanda sig med varandra så att alla atomer hamnar i den eftertraktade wurtzitstrukturen. $\mathrm{Sc}_{\mathrm{x}} \mathrm{Al}_{1-\mathrm{x}} \mathrm{N}$ som är i wurtzitstruktur är därför metastabilt, dvs. det separerar lätt till kubiskt $\mathrm{ScN}$ och hexagonalt AlN. Det finns en låg gräns för hur mycket skandium som kan införas med bibehållen wurtzitstruktur. Jag visar i min avhandling att denna gräns kan höjas avsevärt genom att sänka processtemperaturen från $800^{\circ} \mathrm{C}$ ner till $400^{\circ} \mathrm{C}$. En annan väg att stabilisera $\mathrm{Sc}_{\mathrm{x}} \mathrm{Al}_{1-\mathrm{x}} \mathrm{N}$ med mycket Sc i är att varva lager av $\mathrm{Sc}_{\mathrm{x}} \mathrm{Al}_{1-\mathrm{x}} \mathrm{N}$ med något annat material, tex. indium-aluminiumnitrid $\left(\operatorname{In}_{\mathrm{y}} \mathrm{Al} l_{1-\mathrm{y}} \mathrm{N}\right)$, i så kallade supergritter. Jag undersökte $\mathrm{Sc}_{\mathrm{x}} \mathrm{Al}_{1-\mathrm{x}} \mathrm{N} / \mathrm{In}_{\mathrm{y}} \mathrm{Al}_{1-\mathrm{y}} \mathrm{N}$ multilagerbeläggningar med olika koncentrationer (y) av grundämnet indium (In) för att hitta villkoren som fungerar bäst med olika koncentrationer (x) av Sc i $\mathrm{Sc}_{\mathrm{x}} \mathrm{Al}_{1-\mathrm{x}} \mathrm{N}$.

Den andra delen av min avhandling handlar om det helt outforskade materialet yttrium-aluminium-nitrid $\left(\mathrm{Y}_{\mathrm{x}} \mathrm{Al} l_{1-\mathrm{x}} \mathrm{N}\right)$. Jag är den första att rapportera om tunnfilmer av $\mathrm{Y}_{\mathrm{x}} \mathrm{Al}_{1-\mathrm{x}} \mathrm{N}$ i wurtzitstruktur och detta material är, likt $\mathrm{Sc}_{\mathrm{x}} \mathrm{Al}_{1-\mathrm{x}} \mathrm{N}$, också metastabilt. Jag visar att kristallkvaliteten förbättras genom att i detta fall öka processtemperaturen från $700^{\circ} \mathrm{C}$ upp till $900{ }^{\circ} \mathrm{C}$, detta därför att yttriumatomer är relativt stora och behöver mer energi för att placera sig på rätt ställe i wurtzitstrukturen. Jag har även visat hur de optiska egenskaperna hos $\mathrm{Y}_{\mathrm{x}} \mathrm{Al}_{1-\mathrm{x}} \mathrm{N}$ påverkas genom legering med olika halt av yttrium.

En jämförelse mellan dessa två metastabila material leder till en djupare förståelse för vad som behövs, tex. hur processparametrar ska väljas, för att skapa tidigare oprövade material med bra kristallkvalitet och nya spännande egenskaper som kan lösa olika teknologiska problem. 


\section{Preface}

This dissertation is a product of $\mathrm{PhD}$ studies in the Thin Film Physics Division at Linköping University and summarizes my work done between 2009 and 2013. A part of the results was earlier presented in scientific journals, and the introductory chapters are largely based on my Licentiate thesis No.1524 "Metastable YAlN and ScAlN thin films: growth and characterization", published in 2012 .

The aim of my research was to gain new knowledge in synthesis and characterization of novel ternary wurtzite AlN-based thin films of $\mathrm{Sc}_{\mathrm{x}} \mathrm{Al}_{1-\mathrm{x}} \mathrm{N}$ and $\mathrm{Y}_{\mathrm{X}} \mathrm{Al}_{1-\mathrm{X}} \mathrm{N}$ with enhanced piezoelectric and other application-significant properties. My research was financially supported by Linköping University, the Swedish Research Council, European Research Council, and Swedish Foundation for Strategic Research.

I hope that you will enjoy reading my thesis and that the results will find applications and use in future research.

Linköping, January 2014

A. $\check{Z}$. 


\section{Acknowledgements}

I would like to acknowledge and thank a lot of people, especially:

Jens Birch, my main supervisor - for showing me the way. Your never-ending optimism and fascination with science is inspiring and contagious!

Co-supervisor Lars Hultman - for giving me an opportunity to be a part of Thin Film Physics family and for your immense help with the manuscripts.

My "unofficial" supervisor Gunilla Wingqvist - for being there when it all began and for helping me to become a better scientist. I learned a lot and it was an honor to work with you.

Co-authors - Justinas Pališaitis, Christopher Tholander, Ferenc Tasnádi, Björn Alling, Nebiha Ben Sedrine, Jens Jensen, Esteban Broitman, Per O. Å. Persson, Per Sandström, Hans Arwin, Jun Lu, Vanya Darakchieva, Ramin Matloub, Yunseok Kim, and Paul Muralt - for your help with growth, characterization, theoretical calculations, discussions and your contributions to the manuscripts.

Technical and administrative staff - Inger Eriksson, Camilla Karlsson, Kirstin Kahl, Therese Dannetun, Thomas Lingefelt, Harri Savimäki, and Kalle Brolin, for your help in the confusing worlds of paperwork and swagelok tube fittings.

Colleagues from Thin Film physics, Nanostructure materials, and Plasma \& coatings physics divisions - for your help with the measurements, moral support in the lab, the discussions, and the laughs. Det var roligt att lära sig lite svenska, tack så mycket för de som uppmuntrade mig att prata mer! A very special Thank You goes to my former co-supervisor Anita Lloyd Spetz.

Linköping's Lithuanian community, my friends and my family, and most of all - my husband Martin, for your love and for making me smile every day! 


\section{Included papers}

\section{Paper 1}

\section{Increased Electromechanical Coupling in $\mathrm{w}^{-} \mathrm{Sc}_{\mathrm{x}} \mathrm{Al}_{1-\mathrm{x}} \mathrm{N}$}

Gunilla Wingqvist, Ferenc Tasnádi, Agnè Žukauskaitè, Jens Birch, Hans Arwin, and Lars Hultman

Appl. Phys. Lett. 97, 112902 (2010)

I carried out most of the growth experiments, took part in characterization, discussions, and writing the paper.

\section{Paper 2}

Microstructure and Dielectric Properties of Piezoelectric Magnetron Sputtered w-Sc ${ }_{x} \mathrm{Al}_{1-\mathrm{x}} \mathrm{N}$ Thin Films

Agnė Žukauskaitè, Gunilla Wingqvist, Justinas Pališaitis, Jens Jensen, Per O. Å. Persson, Ramin Matloub, Paul Muralt, Yunseok Kim, Jens Birch, and Lars Hultman

J. Appl. Phys. 111, 093527 (2012)

I carried out most of the growth experiments, took part in characterization and wrote the paper.

\section{Paper 3}

Nanoprobe Mechanical and Piezoelectric Characterization of $\mathrm{Sc}_{\mathrm{x}} \mathrm{Al}_{1-\mathrm{x}} \mathrm{N}(0001)$ Thin Films

Agnè Žukauskaitè, Esteban Broitman, Per Sandström, Lars Hultman, and Jens Birch

Manuscript in final preparation

I planned and carried out most of the growth experiments, took part in characterization and wrote the paper. 


\section{Paper 4}

\section{Stabilization of Wurtzite $\mathrm{Sc}_{0.4} \mathrm{Al}_{0.6} \mathrm{~N}$ in Pseudomorphic Epitaxial $\mathrm{Sc}_{\mathrm{x}} \mathrm{Al}_{1-\mathrm{x}} \mathrm{N} / \mathrm{In}_{\mathrm{y}} \mathrm{Al}_{1-\mathrm{y}} \mathrm{N}$ Superlattices}

Agnè Žukauskaitè, Christopher Tholander, Ferenc Tasnádi, Björn Alling, Justinas Pališaitis, Jun Lu, Per O. A. Persson, Lars Hultman, and Jens Birch

\section{Manuscript in final preparation}

I planned and carried out the growth experiments, took part in characterization and wrote the paper.

\section{Paper 5}

\section{$\mathrm{Y}_{\mathrm{x}} \mathrm{Al}_{1-\mathrm{x}} \mathrm{N}$ Thin Films}

Agnė Žukauskaitè, Christopher Tholander, Justinas Pališaitis, Per O. A. Persson, Vanya Darakchieva, Nebiha Ben Sedrine, Ferenc Tasnádi, Björn Alling, Jens Birch, and Lars Hultman

J. Phys. D: Appl. Phys. 45 (2012) 422001

I planned and carried out the growth experiments, took part in characterization and wrote the paper.

\section{Paper 6}

\section{Bandgap Engineering and Optical Constants of $\mathrm{Y}_{\mathrm{x}} \mathrm{Al}_{1-\mathrm{x}} \mathrm{N}$ Alloys}

Nebiha Ben Sedrine, Agnė Žukauskaitè, Jens Birch, Lars Hultman, and Vanya Darakchieva

Jap. J. Appl. Phys. 52 (2013) 08JM02

I planned and carried out the growth experiments, took part in characterization, discussions, and writing the paper. 


\section{Related papers}

Wurtzite Structure $\mathrm{Sc}_{1-\mathrm{x}} \mathrm{Al}_{\mathrm{x}} \mathrm{N}$ Solid Solution Films Grown by Reactive Magnetron Sputter Epitaxy: Structural Characterization and First-Principles Calculations

Carina Höglund, Jens Birch, Björn Alling, Javier Bareño, Zsolt Czigány, Per O.A. Persson, Gunilla Wingqvist, Agnẻ Žukauskaite, and Lars Hultman

J. Appl. Phys. 107, 123515 (2010)

Anomalously High Thermoelectric Power Factor in Epitaxial ScN Thin Films

Sit Kerdsongpanya, Ngo Van Nong, Nini Pryds, Agnè Žukauskaitė, Jens Jensen, Jens Birch, Jun Lu, Lars Hultman, Gunilla Wingqvist, and Per Eklund

Appl. Phys. Lett. 99, 232113 (2011)

Optical phonons and infrared dielectric functions of wurtzite $\mathbf{Y}_{\mathrm{x}} \mathrm{Al}_{1-\mathrm{x}} \mathrm{N}$

Nebiha Ben Sedrine, Agnè Žukauskaitè, Jens Birch, Jens Jensen, Lars Hultman, Stefan Schoeche, Mathias Schubert, and Vanya Darakchieva

Manuscript in final preparation

Band gap energies and infrared active phonons in wurtzite $\mathrm{Sc}_{\mathrm{x}} \mathrm{Al}_{1-\mathrm{x}} \mathrm{N}$

Nebiha Ben Sedrine, Agnè Žukauskaitè, Jens Birch, Jens Jensen, Lars Hultman, and Vanya Darakchieva

Manuscript in final preparation 


\section{Table of contents}

1 Introduction 1

1.1 Piezoelectricity 2

2 Materials 5

2.1 Sc-Al-N

2.1.1 AlN 5

$\begin{array}{ll}2.1 .2 \mathrm{ScN} & 7\end{array}$

2.1.3Scx $A l_{1-x} N \quad 8$

2.1.4 $\operatorname{In}_{x} A l_{1-x} N$

2.2 Y-Al-N 9

2.2.1YN 9

2.2.2 $Y_{x} A l_{1-x} N \quad 10$

$\begin{array}{ll}2.3 \mathrm{TiN} & 10\end{array}$

3 Growth 11

3.1 Physical vapor deposition 11

3.2 Reactive DC magnetron sputter epitaxy 12

3.3 Epitaxy, strain, and stress 14

3.4 Growth of binary and ternary AlN-based thin films 15

3.5 Growth of superlattice structures 20

4 Modeling 23

4.1 Phase stability predictions 24

4.1.1 Phase stability and lattice mismatch 26

4.2 Expected properties 26

5 Characterization $\quad 27$

5.1 Structural and mechanical properties 27

$\begin{array}{ll}5.1 .1 X \text {-ray diffraction } & 27\end{array}$

5.1.2 Transmission electron microscopy 32

5.1.3 Atomic force microscopy $\quad 36$ 
5.1.4 Nanoindentation $\quad 37$

5.2 Chemical composition 38

5.2.1 Rutherford backscattering spectrometry 38

5.2.2 Elastic recoil detection analysis $\quad 40$

5.3 Optical, electrical, and piezoelectrical properties 41

5.3.1 Spectroscopic ellipsometry 41

5.3.2 Electrical characterization $\quad 42$

5.3.3 Piezoresponse force microscopy 44

5.3.4 Piezoelectric nanoindentation $\quad 45$

5.3.5 Other ways to determine the piezoelectric response 46

6 Summary of included papers

7 Contribution to the field

8 Future work $\quad 55$

$\begin{array}{ll}9 \text { References } & 57\end{array}$

$\begin{array}{ll}\text { Paper } 1 & 65\end{array}$

$\begin{array}{ll}\text { Paper } 2 & 71\end{array}$

$\begin{array}{lr}\text { Paper } 3 & 81\end{array}$

$\begin{array}{lr}\text { Paper } 4 & 99\end{array}$

$\begin{array}{lr}\text { Paper } 5 & 121\end{array}$

$\begin{array}{lr}\text { Paper } 6 & 129\end{array}$ 


\section{Chapter 1}

\section{Introduction}

The idea of changing the surface properties by applying a thin coating on top of a material is certainly not new. Already more than 1000 years ago ceramic glaze was used to decorate pottery as well as make it water-tight. Today, thin films can be found in many different areas of our everyday life. Some of them are used to prolong the lifetime of a cutting tool, others for decorative or optical purposes and many other applications. But while a lot of thin films can be considered to be passive layers, there is also a wide spectrum of functional thin films that, not only change surface properties, but also actively interact with the environment.

An example of a functional property of a thin film is piezoelectricity. It enables a conversion between electrical and mechanical energy and is key to manufacturing of transducers and frequency filters - components of a standard mobile phone. This technology is based on a simple resonator - a piece of piezoelectric material between two electrodes. In thickness mode, a bulk acoustic wave (BAW) is reflecting between the electrode plates [1]. The resonance frequency is inversely proportional to the thickness of the piezoelectric material, so for high-frequency applications (for example telecommunications) thin films are needed. Such devices are called thin film bulk acoustic wave resonators (TFBAR). In the most common ladder filter configuration, several TFBARs with different resonant frequencies are connected in series. AlN is a well-established material for such devices [2] because of its high electrical quality factor $Q$ which allows narrow and sharp frequency bands, as well as its compatibility with the manufacturing processes such as different material synthesis methods and photolithography. 
The main focus of my research is functional AlN-based thin films. Alloying AlN with ScN has been shown to enhance the piezoelectric response of thin films [3]. The $\mathrm{Sc}_{\mathrm{x}} \mathrm{Al}_{1-\mathrm{x}} \mathrm{N}$ system is relatively unexplored, and a large portion of phasestability and structural investigations in the full concentration range were performed here, in the Thin Film Physics division at IFM, Linköping University by Dr. Carina Höglund [4-7]. The next step - focusing on the dielectric properties and the relationship between the microstructure and the piezoelectric response of AlNrich wurtzite ScAlN is presented in this thesis.

$\mathrm{Sc}_{\mathrm{x}} \mathrm{Al}_{1-\mathrm{x}} \mathrm{N}$ was a starting point and it opened doors to a completely new material system: $\mathrm{Y}_{\mathrm{x}} \mathrm{Al}_{1-\mathrm{x}} \mathrm{N}$. Comparing these two alloys gives a possibility to improve our understanding of film growth mechanisms in metastable materials.

The presented work is organized as follows: Chapter 2 deals with materials that were used in this research, giving some basic information about the crystal structure and material properties. Chapter 3 addresses the growth of thin films and focuses on reactive magnetron sputter epitaxy. At the end of the chapter some specific details on growth of $\mathrm{Sc}_{\mathrm{x}} \mathrm{Al}_{1-\mathrm{x}} \mathrm{N}, \mathrm{Y}_{\mathrm{x}} \mathrm{Al}_{1-\mathrm{x}} \mathrm{N}$, and related materials are given. Since my research involved a lot of collaboration with theoreticians, Chapter 4 gives a very brief introduction into $a b$ initio calculations and their use to predict phase stability. Chapter 5 attends to describing various characterization techniques used to investigate the samples. Finally, a short summary of included papers is presented in Chapter 6, contribution to the field in Chapter 7, and some ideas about future work in Chapter 8, respectively.

I would like to finish this introductory chapter with a short section on piezoelectricity. For me, this fascinating material property was where it all began and the main motivation to investigate wurtzite $\mathrm{Sc}_{\mathrm{x}} \mathrm{Al}_{1-\mathrm{x}} \mathrm{N}$ and similar materials.

\subsection{Piezoelectricity}

The phenomenon of piezoelectricity was discovered by Piere and Jacques Curie in 1880. They noticed that some crystals start developing opposite charges on their surfaces when pressure is applied. According to Cady in Ref. [8] (published in 1946), the definition of piezoelectricity is: "electric polarization 
produced by mechanical strain in crystals belonging to certain classes, the polarization being proportional to the strain and changing sign with it”. This is the so-called direct piezoelectric effect, while a converse effect is when the material is mechanically strained by an applied electric field. These two piezoelectric phenomena are interchangeable, so neither the direct nor the converse effect is more fundamental and the naming convention is historical [9]. Mathematically the relationships can be expressed as follows:

$$
\begin{aligned}
& P_{i}=e_{i j k} \cdot S_{j k} \quad \text { (direct), } \\
& S_{i j}=d_{i j k} \cdot P_{k} \text { (converse), }
\end{aligned}
$$

where $P$ is the polarization, $S$ - the strain tensor, $e_{i j k}$ and $d_{i j k}$ are the third-rank piezoelectric tensors, symmetric over the last two indices. The first index (i) indicates the direction of the dielectric displacement, and the second index $(j)-$ the mechanical deformation [10]. For example, piezoelectric coefficient $d_{33}$ would mean that both electric field and mechanical deformation are observed along the same polar axis.

Piezoelectric materials are a sub-class of dielectrics. By definition, a dielectric material is an insulating material that does not conduct electric current, because unlike metals, a dielectric has no free (or loosely bound) electrons. Even so, electrical and optical properties of a dielectric material can be influenced by applying an external electric field, causing polarization. This means that the charges inside the material will separate, but the displacement will be finite. The induced polarization $P$ will be parallel, and the displacement $D$ will be proportional to the electric field $E$ :

$$
\begin{aligned}
& P=\varepsilon_{0} \cdot \chi_{e} \cdot E, \\
& D=\varepsilon \cdot E,
\end{aligned}
$$

where $\chi_{e}$ is the electric susceptibility, $\varepsilon=\varepsilon_{0} \cdot\left(1+\chi_{e}\right)$ is the electric permittivity, $\varepsilon_{0}=8.85 \cdot 10^{-12} \mathrm{~F} / \mathrm{m}$ is permittivity of free space, and $\varepsilon / \varepsilon_{0}=1+\chi_{e}$ is the dielectric constant, or relative electric permittivity. A relative dielectric constant $\varepsilon_{r}=\varepsilon / \varepsilon_{0}$ is a material-dependent property and is further discussed in Section 5.3.2.

The ability of a material to have piezoelectric properties depends on its crystal structure while the actual extent of the piezoelectric effect is material- 
dependent. Out of 32 existing crystal classes 21 are non-centrosymmetric. All noncentrosymmetric crystal classes except the cubic class 432 have been identified as structures that could exhibit piezoelectric properties. 10 out of the remaining 20 are polar crystal classes, such as wurtzite, that demonstrate spontaneous polarization - a non-vanishing electric dipole moment resulting from the asymmetry in the unit cell [11]. Materials with such polar crystal structures also possess pyroelectric properties (becoming electrically charged when heated). Measuring the pyroelectric current is one of the ways to check if the material exhibits the spontaneous polarization. If the dipole moment can be reversed the material is called ferroelectric. One example is lead zirconate titanate $\mathrm{Pb}\left[\mathrm{Zr}_{\mathrm{x}} \mathrm{Ti}_{1-\mathrm{x}}\right] \mathrm{O}_{3}$, also known as PZT.

There are many different applications for piezoelectric materials and most of them can be divided into two groups: sensors and actuators. In sensor applications, the direct piezoelectric effect is usually used for force, pressure, or strain detection. The converse piezoelectric effect is more useful for actuators - generation of surface or bulk acoustic waves (SAW, BAW) as well as resonant sensors where the resonant frequency of the material is changing when it interacts with the environment, for example - biological and chemical sensing applications.

Wurtzite AlN belongs to one of the above mentioned 10 polar crystal classes and exhibits both spontaneous and piezoelectric polarization. Compared to other group III nitrides it has the highest piezoelectric response: $e_{33}=1.46 \mathrm{C} / \mathrm{m}^{2}[12]$ and $d_{33}=5.1-6.72 \mathrm{pm} / \mathrm{V}$ [13-15]. When the stress is applied in the direction of polarization, the $\mathrm{N}-\mathrm{Al}-\mathrm{N}$ bond angle will change, producing a relative displacement of positive and negative charges within the unit cell, which is the origin of the piezoelectricity in AlN [16]. The piezoelectric polarization is always along the [0001] direction and cannot be reversed by external electric fields. 


\section{Chapter 2}

\section{Materials}

This thesis is focused on ternary nitrides, where group IIIA nitride AlN is alloyed with group IIIB nitrides ScN and YN (group numbering according to the CAS nomenclature). In this chapter both binary nitrides used in alloying and resulting ternary nitrides are presented. A short section on TiN, used as a seed layer and a bottom electrode in Paper 1 and Paper 2, is included as well.

\subsection{Sc-Al-N}

\subsubsection{AlN}

Aluminium nitride in its wurtzite phase (Fig. 2.1) is a wide band gap $(6.2 \mathrm{eV}$ [17]) dielectric material. AlN was discovered as a product of reaction between molten aluminum and nitrogen by F. Briegler and A. Geuther in 1862, and first synthesized by J.W. Mallets in 1877 [18]. Research into physical properties of AlN started in the late 1950s, especially in the field of insulating refracting materials. In those days, the main synthesis method was pressure or reactive sintering, resulting in a porous material. Low density issues were eventually solved by additives and the material quality improved tremendously. To my knowledge, reactively sputtered AlN was first reported by J. Duchêne in 1971 [19], and highquality AlN with possibilities for electronic applications emerged in 1990s. It is known for its high temperature stability and good mechanical properties. Moreover, its high acoustic velocity and dielectric qualities made it a popular choice in electroacoustic and optoelectronic applications [20]. 
Wurtzite AlN consists of two hexagonal close-packed lattices - one with Al and another with $\mathrm{N}$ atoms that are displaced one from another vertically (Fig. 2.1). Each $\mathrm{Al}$ atom is bonded tetrahedrally to four $\mathrm{N}$ atoms and vice versa. Such structure can be described by three parameters: lattice constant $c$, which is the height of the cell, lattice constant $a$, which is the edge length of the base, and $u$, which is the bond length between cation and anion ( $\mathrm{Al}$ and $\mathrm{N}$ atoms) expressed in units of $c$. There is no inversion symmetry along the $c$-axis, and all group IIIA nitrides ( $\mathrm{AlN}, \mathrm{InN}$, and $\mathrm{GaN}$ ) experience the spontaneous polarization described in Chapter 1 . The bond length ratio is a very important and material specific parameter as it is related to the polarization strength. In the case of an ideal wurtzite crystal structure, $u=0.375$. The theoretically predicted "real" AlN has $u=0.382$ [21], experimentally obtained lattice constants found in literature are $a=3.11 \AA$ and $c=4.98 \AA$ [22]. As mentioned in the introduction, the piezoelectric coefficient $d_{33}$ for $\mathrm{AlN}$ is in the range of 5.1-6.72 pm/ $/ \mathrm{V}$ - the highest value among group IIIA nitrides [23].

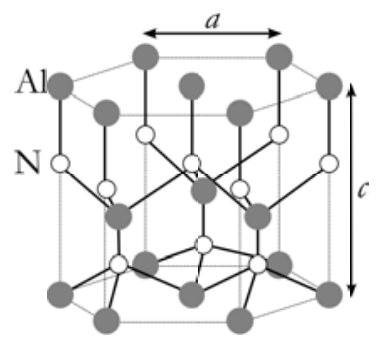

Figure 2.1. Wurtzite structure of AlN.

Since each atomic layer consists of only one type of atoms, the synthesized material can be terminated with either $\mathrm{Al}$ or $\mathrm{N}$, so called $\mathrm{Al}$-face or $\mathrm{N}$-face. The growth polarity determines the direction of the previously mentioned spontaneous polarization. Different approaches and possible explanations on how to control the polarity, such as substrate and seed layer choice [24], growth parameters [25], or doping of the interface [26] are of great interest. Also, though this thesis is concentrated on polar ( $c$-axis oriented) AlN based materials to promote the piezoelectric properties, there are applications such as light emitting diodes (LED), where the built-in polarization is limiting the recombination rate and thus the 
efficiency. In such cases, a non-polar orientation of the material, for example with the growth direction perpendicular to $c$-axis, is preferred [27]. Another potential application for tilted AlN thin films is biosensors, where measurements are performed in liquid, so the shear mode wave propagation has to be promoted [28].

Under special conditions, zinc-blende structure AlN is possible, and at high pressures and temperatures AlN can also be synthesized in a cubic phase, for example as epitaxial films onto $\mathrm{Si}$ substrates [29] or stabilized in a TiN/AlN superlattice [30].

In my research, the w-AlN films served mostly as a starting point for optimizing growth parameters and as reference during the characterization. Different aspects of using reactive magnetron sputtering for growth of AlN and related materials are discussed more in detail in Section 3.4.

\subsubsection{ScN}

Scandium is a group IIIB element and is usually considered to be a transition metal. In its most stable form, $\mathrm{ScN}$ has a cubic, rock-salt $(\mathrm{NaCl})$ structure, shown in Fig. 2.2 (a), but recently a theoretical study showed the existence of a metastable nearly fivefold coordinated layered hexagonal phase (h-ScN) [31], Fig. 2.2 (b). Cubic ScN has many properties common for all transition metal nitrides, such as high hardness and high-temperature stability. It is also a wide band gap semiconductor (2-2.4 eV according to Ref. [32]), and its thermoelectric properties were demonstrated experimentally [33].

(a)

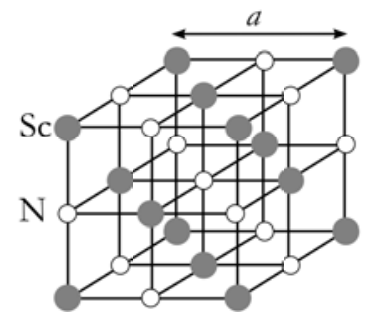

(b)

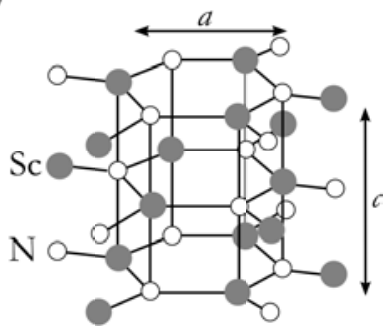

Figure 2.2. Cubic (a) and layered hexagonal (b) structures of ScN.

In my research, $\mathrm{ScN}$ was only used as a seed layer for $\mathrm{Sc}_{\mathrm{x}} \mathrm{Al}_{1-\mathrm{x}} \mathrm{N} / \mathrm{In}_{\mathrm{x}} \mathrm{Al}_{1-\mathrm{x}} \mathrm{N}$ superlattice structures (Paper 4) due to a better in-plane lattice match with $\mathrm{In}_{\mathrm{x}} \mathrm{Al}_{1-\mathrm{x}} \mathrm{N}$ than that of $\mathrm{AlN}$. 


\subsection{3 $S c_{x} A l_{1-x} N$}

The main drawback of AlN that limits the scope of applications is its rather low piezoelectric response (as compared to more conventional piezoelectric materials such as PZT) and electromechanical coupling coefficient $k_{\mathrm{t}}{ }^{2}$. For these reasons, there is a growing interest in finding ways to improve this material, and one way do to that is by alloying and creating new, ternary, nitride materials. In 2009 Akiyama et al. in Ref. [3] reported a 400\% increase in piezoelectric response by alloying AlN with $\mathrm{ScN}$. Later, a theoretical study showed this increase to be an intrinsic effect [34] caused by the aforementioned metastable fivefold layered hexagonal h-ScN phase which weakens the internal resistance against changing cla ratio. In Paper 1 it is shown that $k_{\mathrm{t}}{ }^{2}$ increases from $7 \%$ for $\mathrm{AlN}$ up to $10 \%$ for $\mathrm{Sc}_{0.2} \mathrm{Al}_{0.8} \mathrm{~N}$. Other research groups were successful in manufacturing and testing TFBAR structures with up to $\mathrm{x}=0.12$ [35] and $\mathrm{x}=0.15$ [36,37]. Transverse piezoelectric coefficient $e_{31, f}$ increases by nearly $50 \%$ for $\mathrm{x}=0.17$, making this material attractive for energy harvesting applications [38]. SAW devices on $6 \mathrm{H}$ $\mathrm{SiC}$ were demonstrated for $\mathrm{x}=0.46$ [39].

According to calculations in Ref. [5], alloying results in positive mixing enthalpies, which means that there is an internal driving force towards phase separation in this material, this is also seen experimentally. In Paper 2, I show, however, that the phase separation can be reduced by decreasing the growth temperature from 800 down to $400{ }^{\circ} \mathrm{C}$. Additionally, an increase in piezoelectric response up to $180 \%$ in $\mathrm{Sc}_{0.2} \mathrm{Al}_{0.8} \mathrm{~N}$ as compared to $\mathrm{AlN}$ is demonstrated, thus confirming previously reported results from Ref. [3]. Effect of lattice mismatch was studied and, as a result, $\mathrm{Sc}_{0.4} \mathrm{Al}_{0.6} \mathrm{~N}$ was stabilized in a superlattice structure with $\mathrm{In}_{0.72} \mathrm{Al}_{0.28} \mathrm{~N}$ (Paper 4).

\subsection{4 $\operatorname{In}_{x} A l_{1-x} N$}

Indium belongs to group IIIA, but it is much heavier than $\mathrm{Al}$ and melts at $157^{\circ} \mathrm{C}$. Indium nitride has the same crystal structure as $\mathrm{AlN}$, i.e. wurtzite (Fig. 2.1). It is less stable than GaN and AlN due to low bonding energy between In and $\mathrm{N}$, as well as low dissociation temperature [40]. A miscibility gap between $\mathrm{InN}$ and AlN complicates the growth of $\operatorname{In}_{x} \mathrm{Al}_{1-\mathrm{x}} \mathrm{N}$, and studies show a decomposition 
tendency in samples with In content $0.15<\mathrm{x}<0.79$ during the thermal treatment up to $\mathrm{T}=1000 \mathrm{~K}$ [41]. However, using reactive magnetron sputtering at low growth temperatures it is possible to produce single phase $\operatorname{In}_{\mathrm{x}} \mathrm{Al}_{1-\mathrm{x}} \mathrm{N}$ in the full range of composition [42]. Due to the possibility of tuning the direct band gap in a wide spectral range between $0.64 \mathrm{eV}(\mathrm{InN})$ and $6.2 \mathrm{eV}(\mathrm{AlN})$ this material is of interest for optoelectronic applications such as LEDs and laser diodes.

Since both InN and AlN are wurtzite, Vegard's rule - linear relationship between the stoichiometry of a ternary compound and the lattice parameter ( $a$ or $c$ ) [43] - can be applied:

$$
a\left(\operatorname{In}_{z} A l_{1-x} N\right)=a_{A I N}+a_{I n N} x .
$$

However, it should be noted that sputtered $\mathrm{InN}$ contains point defects that cause lattice parameters $c$ and $a$ to become larger than standard values obtained by other methods [44]. This should be accounted for when deciding upon what composition is needed. $\operatorname{In}_{\mathrm{x}} \mathrm{Al}_{1-\mathrm{x}} \mathrm{N}$ was used in Paper 4 to lattice match and to tensely stress $\mathrm{Sc}_{\mathrm{x}} \mathrm{Al}_{1-\mathrm{x}} \mathrm{N}$ in a superlattice structure in order to investigate the influence of in-plane lattice mismatch on the stability of $\mathrm{Sc}_{\mathrm{x}} \mathrm{Al}_{1-\mathrm{x}} \mathrm{N}$.

\subsection{Y-Al-N}

\subsubsection{YN}

Yttrium belongs to the group IIIB, same as scandium, though according to different literature sources, its properties are closer to lanthanides than to transition metals. It is a highly reactive element.

YN can be synthesized in a cubic structure (same as Fig. 2.2 (a) for $\mathrm{ScN}$ ), but unlike ScN, it forms oxide-hydroxides $\mathrm{YOOH}$ when exposed to moist air [45], hence a $5 \mathrm{~nm}$ thick capping layer of amorphous AlN is suggested by Gregoire et al. in Ref. [45]. Reported values for its direct band gap range from $1.5 \mathrm{eV}$ [46] to $2.3 \mathrm{eV}$ [47], and the indirect band gap of $0.498 \mathrm{eV}$ was recently reported [48]. For comparison, previously calculated theoretical values are $0.85 \mathrm{eV}$ [49] and $0.54 \mathrm{eV}$ [50]. Investigations of possible uses for YN include buffer layer for GaN thin films [51], phase-stabilization of Cr-Al-Y-N coatings [52,53], and for improving the oxidation 
resistance of Ti-Al-N based coatings [54]. It was also demonstrated that AlN nanorods doped with Y possess ferromagnetic properties [55].

\subsection{2 $Y_{x} A l_{1-x} N$}

Knowledge gained from alloying $\mathrm{AlN}$ with $\mathrm{ScN}$ was applied to grow ternary AlN-rich $\mathrm{Y}_{\mathrm{x}} \mathrm{Al}_{1-\mathrm{x}} \mathrm{N}$. Reactively sputtered YAlN thin films have not been reported before; previous investigations are limited to bulk YN-rich YAlN [56] and theoretical calculations of mixing enthalpies presented in relation to the $\mathrm{Cr}-\mathrm{Al}-\mathrm{Y}-\mathrm{N}$ system [53]. The most similar material system investigated experimentally to this day is $\mathrm{Y}_{\mathrm{x}} \mathrm{In}_{1-\mathrm{x}} \mathrm{N}$ in Ref. [48].

Large volume difference between $\mathrm{Al}$ and $\mathrm{Y}$ means that mixing enthalpies for all investigated $\mathrm{Y}_{\mathrm{x}} \mathrm{Al}_{1-\mathrm{x}} \mathrm{N}$ phases (cubic, layered hexagonal, wurtzite) are higher than those for ScAlN. The calculations show that the wurtzite structure is the most favorable in the range $0<x<0.75$, as demonstrated in Paper 5. In comparison, $\mathrm{Sc}_{\mathrm{x}} \mathrm{Al}_{1-\mathrm{x}} \mathrm{N}$ has the lowest mixing enthalpy for the wurtzite structure up to $\mathrm{x}=0.5$ [5]. Spectroscopic ellipsometry was used to determine optical constants and direct band gap of this material (Paper 6).

\section{$2.3 \mathrm{TiN}$}

In order to do electrical and piezoelectric characterization of the $\mathrm{Sc}_{\mathrm{x}} \mathrm{Al}_{1-\mathrm{x}} \mathrm{N}$ films a bottom electrode serving as a seed layer is needed. Apart from electrical properties, relatively good lattice match is of importance too. Cubic TiN (Fig. 2.2) is known for its good mechanical properties and is often used as a hard coating in cutting tool applications. It is also conductive. Reactively sputtered $\operatorname{TiN}(111)$ with inplane lattice spacing $d_{110}=3.00 \AA$ has a rather good lattice match to AlN $(a=3.11 \AA$ A). Epitaxial and smooth films with rocking curve full width at half maximum values $(\mathrm{FWHM}) \leq 0.05^{\circ}$ were grown at $\mathrm{T}_{\mathrm{s}}=800{ }^{\circ} \mathrm{C}$ in $\mathrm{Ar} / \mathrm{N}_{2}$ gas mixture with rather low nitrogen partial pressure. The TiN films proved to be very sensitive to $\mathrm{Al}_{2} \mathrm{O}_{3}$ surface contaminations, so special precautions had to be taken during the substrate preparation. 


\section{Chapter 3}

\section{Growth}

Generally speaking, thin films are synthesized by first transferring source material into gas phase. While in gas phase, the material is transported towards the substrate where it condenses and forms a thin film. Deposition techniques are usually divided into physical vapor deposition (PVD) and chemical vapor deposition (CVD). In the first group, a solid-to-gas phase transformation is done through heating or sputtering, while in the second one the vapor is created and film is formed through chemical reactions [57]. In this thesis all material synthesis was performed employing PVD processes.

\subsection{Physical vapor deposition}

PVD is a term that includes techniques for synthesizing thin films where source material is transformed into gas through a physical process. It can be done through heating (thermal evaporation), high power arc discharge (cathodic arc deposition), ablation of a target with a pulsed laser (pulsed laser deposition) or sputter deposition, where material is turned into vapor through ion bombardment of the source material.

All thin films discussed here were deposited using reactive DC magnetron sputter epitaxy, described in more detail in the following sections. Thermal evaporation was used to deposit $\mathrm{Cr} / \mathrm{Au}$ electrodes on top of the films for electrical and piezoelectrical characterization (Paper 1 and Paper 2). 


\subsection{Reactive DC magnetron sputter epitaxy}

As mentioned in 3.1, sputtering is a PVD technique where a piece of material, so called target, is bombarded by ions. First reported by Grove in 1852 [58] it is now one of dominating processes in the vacuum coating industry. One of the main advantages of using this technique is operating away from the thermodynamic equilibrium conditions so the metastable materials or material phases can be synthesized and investigated.

(a)

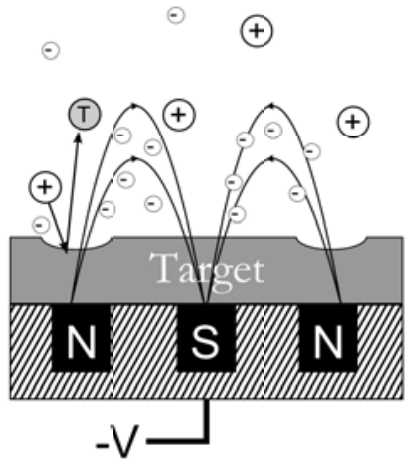

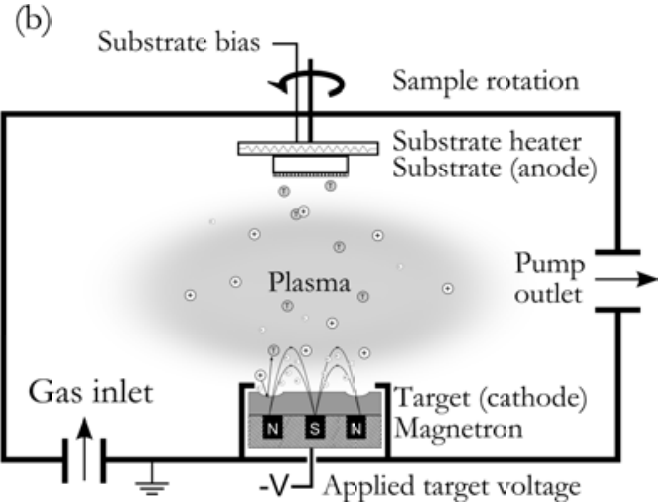

Figure 3.1. Magnetron sputtering process: (a) magnet configuration and species participating in the sputtering process, (b) schematics of a vacuum chamber. N and S represent magnetic polarity, "+" stands for the sputtering gas ion, "-" is a free electron, and "T" is the ejected target atom.

The ions are generated in plasma, which ignites when gas is introduced into the vacuum chamber and a negative potential $U$ is applied to the target. This is possible because there are always some ionized gas atoms and free electrons available due to natural cosmic radiation. The ions are accelerated towards the target while more gas atoms are ionized through collisions with free electrons. When the ions collide with the target surface, target atoms are ejected (sputtered) and transported through the chamber towards the substrate. At the same time, secondary electrons are produced, consequently ionizing more and more gas. The amount of these secondary electrons is directly related to the ionization rate. A set of permanent magnets can be placed behind the target to trap the secondary electrons close to the target surface, thus enhancing the sputtering process. Another advantage of such configuration is that lower gas pressure is needed for plasma ignition and maintaining a stable process. The described film deposition 
method is called magnetron sputtering and it is one of the most common sputtering techniques used today. Trapping electrons with the help of a magnetron was first suggested by Penning in 1935 [58]. Based on the manner of how the negative potential is applied onto the target, different magnetron sputtering modes are possible, such as direct current (DC), pulsed DC, radio frequency (RF), and high power impulse magnetron sputtering (HIPIMS).

In Fig. 3.1, the magnet configuration and the main components of a magnetron sputter deposition chamber are depicted. The target is shown to have a so called erosion track, where more material is sputtered due to higher density of magnetic field lines trapping more secondary electrons and attracting more gas ions (Fig. 3.1 (a)). Magnets can be arranged in different ways, for example, a large ring-shaped magnet and a small magnet in the middle, in other constructions the large ring is replaced by small magnets distributed in a circle. During the sputtering process the magnetrons heat up and have to be cooled (not shown in the figure), otherwise the magnets can overheat and lose their magnetic properties. Quite often the chamber walls are cooled as well to improve the vacuum level by cold-trapping residual gases. The schematic drawing in Fig. 3.1 (b) shows only one magnetron positioned directly in front of the substrate. In reality, deposition chambers are often equipped with two or more tilted magnetrons with the sample positioned in a common focal point, thus allowing co-sputtering from several targets. By changing the applied power the amount of sputtered material can be varied to obtain samples with different compositions. Samples for Paper 1-3 were deposited in a deposition chamber with 3 magnetrons, and for samples presented in Papers 4-6 another deposition chamber, equipped with 4 magnetrons, was used. When using multiple magnetrons, substrate rotation becomes an essential condition to obtain homogeneous films.

The most common gas used in a sputtering process is argon. Due to its inertness it does not interact with sputtered atoms chemically and can be used with any kind of target material. However, under some conditions, for example, when bias voltage is applied to the substrate or the distance between the target and the substrate is relatively short, it can be mechanically trapped in the resulting thin film and affect its morphology [59-61]. In addition to argon, reactive 
gases such as oxygen or nitrogen can be introduced into the chamber. They react with the sputtered atoms both on the target and on the film surface thus forming a compound material, for example, a nitride. Such process is called reactive magnetron sputtering. It was first introduced by Veszi in 1953 to deposit tantalum nitride thin films [58]. The main problem with reactive sputtering is target poisoning: reactive gas reacts with the target surface and forms an insulating layer that charges up and shields the electric field, thus reducing the sputtering rate dramatically. This phenomenon is more common when dealing with oxygen and is usually solved by using RF magnetron sputtering. In the case of group IIIA nitrides reactive DC magnetron sputtering is possible using even pure nitrogen as process gas.

Reactive magnetron sputter epitaxy is an extension of reactive magnetron sputtering, the main difference is that the resulting films are single crystal. That is achieved by maintaining ultra high vacuum conditions ( $10^{-9}$ Torr $)$, ultra-pure target materials, and gas purifiers for the process gasses. In that sense it is rather similar to molecular beam epitaxy (MBE).

\subsection{Epitaxy, strain, and stress}

In 1928, Royer originally defined epitaxy as oriented growth of crystalline material on a single crystal surface [57]. In thin films that means a case when the crystal orientation of the film depends on and "follows" the crystal orientation of the substrate. There are two different types of epitaxial growth: homoepitaxy, when the film and the substrate are of the same material, and heteroepitaxy, when they are different.

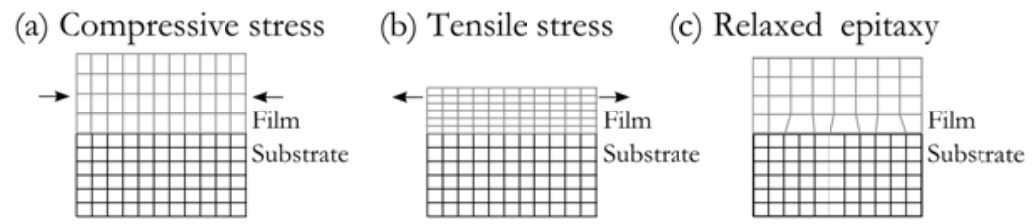

Figure 3.2. Strained-layer epitaxy when (a) substrate in-plane lattice parameter is smaller, (b) film in-plane lattice parameter is smaller, and (c) relaxed epitaxy.

In the case of heteroepitaxy, lattice mismatch between the substrate and the film is usually present. If the mismatch is low, the substrate and film lattices can 
strain to accommodate the differences. Strained-layer epitaxy (Fig. 3.2 (a)-(b)) is common during the early stages of film formation, and such growth is called pseudomorphic. If the lattice mismatch is too high, dislocation defects will form at the interface to minimize the stress (relaxed epitaxy), as shown in Fig.3.2 (c). If the in-plane lattice parameters of the substrate and the film are known, the lattice mismatch $\delta$ can be calculated using eq. 3.1:

$$
\delta=\frac{\left(a_{f}-a_{s}\right)}{a_{s}} \cdot 100 \% \text {. }
$$

Here $a_{f}$ and $a_{s}$ are in-plane lattice spacings of the film and the substrate, respectively. If $\delta>0$, a compressive biaxial stress will develop during the initial stages of the growth, which can lead to a lattice that is compressively strained in the plane of the interface, as shown in Fig. 3.2(a). Conversely, if $\delta<0$, a tensile stress will be present, which may lead to the opposite strain state (Fig. 3.2 (b)). Theoretical predictions, done by Frank and van der Merwe in 1949, show that when the mismatch is lower than $9 \%$, the films would grow pseudomorphically. However, there generally exists a critical film thickness above which the coherency strain starts to relax. For large lattice mismatch systems, this can be as small as an atomic layer.

\subsection{Growth of binary and ternary AlN-based thin films}

There are three possible types of structures in a solid material: amorphous, polycrystalline, and crystalline. In an amorphous material atoms are arranged in a random fashion - long-range order is lacking and no periodicity in the structure is observed. Polycrystalline material is composed of crystallites of varying size, often randomly oriented (Fig. 3.3 (a)). However, the crystallites can have a preferred orientation (texture), for example with common crystal axes in the out-of-plane direction, while in-plane the grains are misaligned (Fig 3.3 (b)), which is a common situation in thin films. Single crystal material has the highest level of order, as there are no grain boundaries and the entire sample is one uninterrupted crystal lattice both in-plane and out of plane (Fig. 3.3 (c)). 
In my research, the most common type of structure was a textured film with a single preferred orientation: a c-axis oriented wurtzite, where all grains (columns) have the same orientation in the growth direction, while in-plane they are slightly misaligned with respect to each other. The film quality of AlN and $\mathrm{Sc}_{\mathrm{x}} \mathrm{Al}_{1-\mathrm{x}} \mathrm{N}$ up to $\mathrm{x}=0.2$ was good enough for epitaxial relationship with the sapphire substrate to be determined: $\mathrm{Sc}_{\mathrm{x}} \mathrm{Al}_{1-\mathrm{x}} \mathrm{N}(0001) \| \mathrm{Al}_{2} \mathrm{O}_{3}(0001)$ out-of-plane and $\mathrm{Sc}_{\mathrm{x}} \mathrm{Al}_{1-\mathrm{x}} \mathrm{N}[10 \overline{1} 0] \| \mathrm{Al}_{2} \mathrm{O}_{3}[11 \overline{2} 0]$ in-plane, which means that the $\mathrm{Sc}_{\mathrm{x}} \mathrm{Al}_{1-\mathrm{x}} \mathrm{N}$ columns are rotated $30^{\circ}$ with respect to $\mathrm{Al}_{2} \mathrm{O}_{3}$ to minimize the lattice mismatch. Such epitaxial relationship is typical for group IIIA nitrides [62]. With higher amounts of Sc or Y the films become polycrystalline - they have no preferred orientation and consist of small, randomly oriented grains.

(a) Polycrystalline

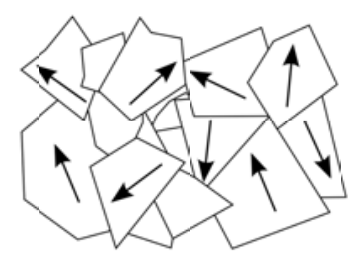

(b) Textured

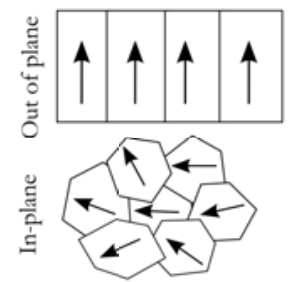

(c) Single crystal

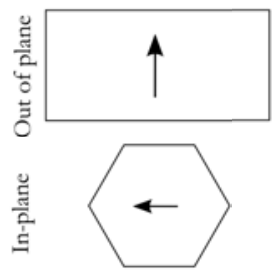

Figure 3.3. Different types of crystalline materials: (a) polycrystalline, (b) textured, and (c) single crystal.

What kind of structure will form during the deposition process depends on a large number of factors. They can be 1) process specific, such as substrate temperature and applied bias voltage, magnetron power and operating mode, gas pressure and composition, as well as vacuum quality; 2) substrate specific surface morphology, composition, contaminations, crystal orientation; 3) film growth specific - type of material, lattice mismatch, or a chemical reaction with the substrate or seed layer, surface mobility of ad-atoms, preferred nucleation sites and so on. In this thesis I discuss general trends that are of importance when dealing with $\mathrm{AlN}, \mathrm{In}_{\mathrm{y}} \mathrm{Al}_{1-\mathrm{y}} \mathrm{N}, \mathrm{Sc}_{\mathrm{x}} \mathrm{Al}_{1-\mathrm{x}} \mathrm{N}$, and $\mathrm{Y}_{\mathrm{x}} \mathrm{Al}_{1-\mathrm{x}} \mathrm{N}$ thin films.

\section{1) $\mathrm{AlN}$ :}

When using reactive DC magnetron sputtering, the stoichiometric wurtzite AlN is not difficult to form, but the film orientation, crystalline and 
microstructural quality depends on the factors mentioned above. In general, piezoelectric and other application-significant properties of AlN, and other group III-nitrides are very sensitive to oxygen contamination [63], so an ultra high vacuum (UHV) growth chamber equipped with gas purifiers and high purity elemental targets is preferred. The substrates should be thoroughly cleaned and thermally degassed prior to the deposition.

In my work, the properties that were used as indicators of quality improvement were the increase of AlN 0002 peak intensity in X-ray diffraction $\theta / 2 \theta$ scan (see Section 5.1.1), decrease of $\omega$-FWHM value, and the decrease of the roughness observed using the atomic force microscopy (see Section 5.1.3). It is known that high ad-atom mobility is needed for epitaxial growth of the stable binary wurtzite phase [64]. At lower total gas pressures (less than $\sim 1 \mathrm{~Pa}$ ) the sputtered species arrive at the substrate with higher than thermal energies. Additional energy is supplied to the growth by substrate heating. It is also known that a high partial pressure of $\mathrm{N}_{2}$ reduces the ad-atom mobility, which, on the other hand may be increased by a low negative substrate bias voltage. This explains why the best results were obtained when the growth temperature was higher than $600{ }^{\circ} \mathrm{C}$ [65] and using an $\mathrm{Ar} / \mathrm{N}_{2}$ mixture at relatively low pressures and low $\mathrm{N}_{2}$ content as compared to the depositions at higher process pressures or depositions in pure $\mathrm{N}_{2}$ that resulted in increased surface roughness. The samples discussed in Paper 1-3 were deposited at a floating substrate potential, and in Papers 4-6 a substrate DC bias of - 15 to $-30 \mathrm{~V}$ was applied.

Thin amorphous AlN capping layers (see below, in a section on $\mathrm{Y}_{\mathrm{x}} \mathrm{Al}_{1-\mathrm{x}} \mathrm{N}$ ) were deposited at $150{ }^{\circ} \mathrm{C}$ using no applied substrate bias and 10 mTorr $\mathrm{N}_{2}$ process pressure, thus preventing crystallization.

2) $\operatorname{In}_{\mathrm{y}} \mathrm{Al}_{1-\mathrm{y}} \mathrm{N}$ :

Thin films of $\operatorname{In}_{\mathrm{y}} \mathrm{Al}_{1-\mathrm{y}} \mathrm{N}$ were grown as part of the $\mathrm{Sc}_{\mathrm{x}} \mathrm{Al}_{1-\mathrm{x}} \mathrm{N} / \mathrm{In}_{\mathrm{y}} \mathrm{Al}_{1-\mathrm{y}} \mathrm{N}$ superlattice study in order to determine the magnetron powers needed to obtain certain $\mathrm{In} / \mathrm{Al}$ ratios. $\mathrm{In}_{\mathrm{y}} \mathrm{Al}_{1-\mathrm{y}} \mathrm{N}$ stabilization layers were used to provide lattice match or negative lattice mismatch with the $\mathrm{Sc}_{\mathrm{x}} \mathrm{Al}_{1-\mathrm{x}} \mathrm{N}$ layers (Paper 4). Vegard's rule was applied to extract in-plane lattice parameters and film composition from 
x-ray diffraction scans. The growth parameters were based on an extensive study of reactive magnetron sputtered $\operatorname{In}_{\mathrm{y}} \mathrm{Al}_{1-\mathrm{y}} \mathrm{N}$ by Dr. T. Seppänen [66-68]

Additionally, In-rich $\operatorname{In}_{\mathrm{y}} \mathrm{Al}_{1-\mathrm{y}} \mathrm{N}$ nanorods with no core-shell structure were obtained (Fig. 3.4). Core-shell structure where In/Al ratio is different at the core of the nanorod and on the outside (shell) is a known issue, and depending on application, and the sharpness of the interface can be both an advantage and a disadvantage. Initial studies suggest that the core-shell structure was eliminated due to process conditions, in particular the process gas, but further investigations are required.
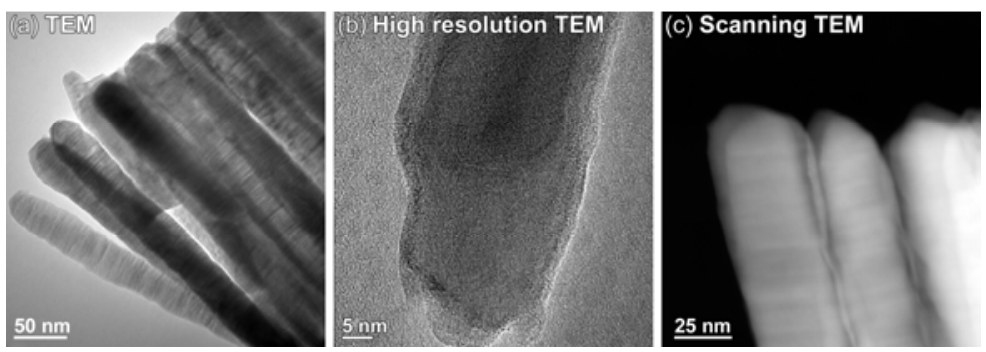

Figure 3.4. Micrographs of In-rich In-AlN nanorods without core-shell structure obtained in a transmission electron microscope: (a) overview, (b) high resolution, and (c) mass-contrast in scanning TEM mode.

3) $\mathrm{Sc}_{\mathrm{x}} \mathrm{Al}_{1-\mathrm{x}} \mathrm{N}$ :

As mentioned in Section 2.1 alloying $\mathrm{ScN}$ with $\mathrm{AlN}$ results in positive mixing enthalpies meaning that the $\mathrm{Sc}_{\mathrm{x}} \mathrm{Al}_{1-\mathrm{x}} \mathrm{N}$ films are considered to be metastable. The amount of Sc in the films is controlled by adjusting the relative applied target power. The total $\mathrm{Al}+\mathrm{Sc}$ power was kept constant at $150 \mathrm{~W}$ in Papers 1-3. Growth experiments were performed at different temperatures, ranging from room temperature up to $800{ }^{\circ} \mathrm{C}$. Films deposited at $400{ }^{\circ} \mathrm{C}$ proved to possess the best characteristics such as high crystalline quality and low leakage currents. Based on the fact that films deposited at higher temperature showed indications of elemental segregation into $\mathrm{ScN}$-rich and AlN-rich domains, it is possible that the mobility of species on the film surface is too high when $\mathrm{T}_{\mathrm{s}} \geq 600{ }^{\circ} \mathrm{C}$, resulting in an increased tendency for decomposition. The effect of an applied substrate bias in combination with lowering the growth temperature is yet to be investigated. 
While it is possible to grow AlN even using pure $\mathrm{N}_{2}$ as process gas, the Sc targets proved to be very sensitive to surface poisoning and the process becomes unstable if the $\mathrm{Ar} / \mathrm{N}_{2}$ mixture is nitrogen rich.

4) $\mathrm{Y}_{\mathrm{x}} \mathrm{Al}_{1-\mathrm{x}} \mathrm{N}$ :

The experiments were performed in a UHV chamber equipped with $75 \mathrm{~mm}$ diameter $\mathrm{Al}$ target and $50 \mathrm{~mm}$-diameter $\mathrm{Y}$ target. The $\mathrm{Y}$ concentration was controlled in the same manner as $\mathrm{Sc}$ in the $\mathrm{Sc}_{\mathrm{x}} \mathrm{Al}_{1-\mathrm{x}} \mathrm{N}$ films, but now the total $\mathrm{Al}+\mathrm{Y}$ power was kept at $350 \mathrm{~W}$. In comparison to Sc, Y has a much larger atomic volume and is known to oxidize rapidly when exposed to air, consequently new challenges and problems arise compared to growth of $\mathrm{Sc}_{\mathrm{x}} \mathrm{Al}_{1-\mathrm{x}} \mathrm{N}$. A thin layer of amorphous AlN had to be deposited on top of the films prior to exposing them to atmosphere for protection against oxidation. The time of flight elastic recoil detection analysis (ToF-E ERDA, see Section 5.2.2) results presented in Paper 5 proved it to be effective.

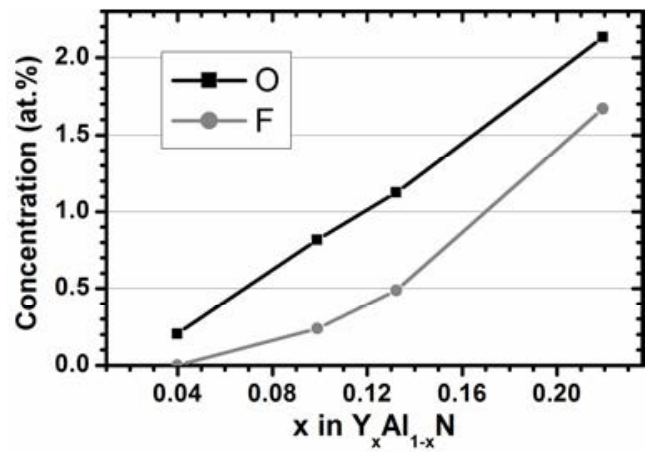

Figure 3.5. Levels oxygen and fluorine as a function of yttrium concentration in $\mathrm{Y}_{\mathrm{x}} \mathrm{Al}_{1-\mathrm{x}} \mathrm{N}$ thin films with $\mathrm{x}=0.04-0.22$.

However, the elemental target itself contained a lot of impurities such as $\mathrm{O}, \mathrm{F}$, $\mathrm{Cr}$, and possibly $\mathrm{W}$ which were transferred into the films. It has been previously reported that during the growth of pure YN yttrium acts as a getter for residual gases [51]. This resulted in films containing a substantial amount of oxygen (up to 2.2 at.\%) and fluorine, the amounts of which increase with the Y concentration (Fig. 3.5). 
The growth experiments (Paper 5) also showed that the crystalline quality of the $\mathrm{Y}_{\mathrm{x}} \mathrm{Al}_{1-\mathrm{x}} \mathrm{N}$ films improved with temperature, which is an opposite trend from the one observed in $\mathrm{Sc}_{\mathrm{x}} \mathrm{Al}_{1-\mathrm{x}} \mathrm{N}$.

\subsection{Growth of superlattice structures}

Though the sequential deposition of two different metals was attempted already in 1923 by Koeppe, and by Deubner in 1930 [69,70], for synthetically layered structures the term superlattice was first introduced by Esaki and Tsu in 1970 [71]. Here, a superlattice (SL) is considered an artificial periodic structure that consists of alternate epitaxial layers of two different materials (Fig. 3.6). The layer thicknesses are typically in the order of nanometers. Often, the SL is produced from materials that have the same crystal structures and similar lattice parameters, making the epitaxial growth of a single crystal SL possible. Since 1970, this ingenious idea was used to produce many different structures, for example, quantum wells (QW), multiple QW (MQW), single crystal SL and other nano-scale structures exhibiting electronic, magnetic or optical properties that do not exist in "natural" crystals. If the periodic layered structure has no crystallographic coherence between the layers it should be referred to as a multilayer (ML).

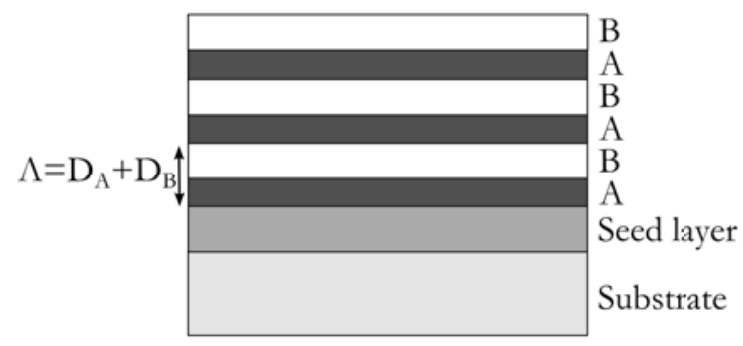

Figure 3.6. A schematic drawing of a superlattice structure.

While there are multiple applications for ML and SL structures, this new degree of freedom introduces additional difficulties in the film growth process. Periodicity, clear separation between the layers and layer repeatability is crucial, therefore very accurate growth rate calibration is required, as well as strict process control. Also, the SL properties can depend on the stacking order (ABAB or 
BABA), SL period $(\Lambda)$, individual thicknesses of layers, and total number of bilayers.

In the case of reactive magnetron sputtering, magnetron shutters are opened and closed regularly to expose the sample to fluxes of different materials to artificially build a periodic structure layer by layer. To produce a superlattice with abrupt interfaces between the layers the shutters have to move as fast as possible and cover the "unwanted" magnetron target completely. In my research (Paper 4) magnetic coils mounted on the shutter rods were remotely controlled through a custom-made computer program written by Dr. Per Sandström. That way the growth time of each individual layer could be controlled with the precision of 0.1 second. Growth rate calibration was mainly based on x-ray reflectivity (XRR) measurements described in Section 5.1.1. 


\section{Chapter 4}

\section{Modeling}

Our theoretical understanding of materials is constantly improving. At the same time, computers get cheaper and more powerful, while experimental resources become more expensive. For this reason, theoretical calculations and modeling are often used in a search for new stable phases, predicting materials with enhanced properties, as well as to explain the formation of metastable thin films and the driving forces inside them.

Ternary nitrides are not an exception. All theoretical results discussed in this thesis are based on first principle ( $a b$ initio) calculations within density-functional theory (DFT) [72] using the Vienna Ab Initio Simulation Package (VASP) [73,74], which utilizes the Projected Augmented Wave (PAW) [75] method, together with the General Gradient Approximation (GGA) [76] pseudopotential. The calculations are done in an iterative fashion where, after initial setting up of a structure, energy minimization and structure relaxation are performed, optimizing the parameters at every cycle until desired accuracy is achieved. In order to accurately model the randomness of pseudobinary $\mathrm{A}_{\mathrm{x}} \mathrm{B}_{1-\mathrm{x}} \mathrm{C}$ alloys the special quasi-random structure method (SQS) is used [77]. In ternary $\mathrm{Sc}_{\mathrm{x}} \mathrm{Al}_{1-\mathrm{x}} \mathrm{N}$ and $\mathrm{Y}_{\mathrm{x}} \mathrm{Al}_{1-\mathrm{x}} \mathrm{N}$ it results in the ordered nitrogen sublattice, while in the metal sublattice the $\mathrm{Al}$ and $\mathrm{Y}$ or $\mathrm{Sc}$ atoms are distributed in a structure that best reproduces the short-range ordering of a random alloy, but keeping the typical bond length - a rather realistic representation of such material system. The drawback of using SQS is that supercells have to be relatively big (for example 128 atoms) to obtain reliable 
results, which increases the calculation time. For binary alloys such as AlN, ScN or $\mathrm{YN}$, the modeled cells can be much smaller as no randomization is needed.

Theoretical calculations can be based on empirical data. However, the experimental outcome can be influenced by many different factors, thus affecting the reliability and accuracy of such modeling. When $a b$ initio calculations are utilized, no experimental data are needed as a starting point. Instead, one starts with the Schrödinger's equation. As it is not possible to directly solve it for more than two particles, certain approximations have to be used. One of the most common approaches is the DFT formalism, where the properties of a system can be described by electron density functionals [72] - considering the nuclei to be immobile and using only the average number of electrons at a point in space to calculate all other properties. For developing this method, a Nobel Prize in Chemistry was awarded to W. Kohn in 1998.

$A b$ initio calculations are often used for Ti-Al-N and other related systems. $\mathrm{Sc}_{\mathrm{x}} \mathrm{Al}_{1-\mathrm{x}} \mathrm{N}$ has also received quite a lot of attention. Results from mixing enthalpy calculations for cubic, hexagonal and wurtzite structures as well as lattice constants are presented and described in detail in Ref. [5,7,78]. $\mathrm{Y}_{\mathrm{x}} \mathrm{Al}_{1-\mathrm{x}} \mathrm{N}$ results from collaboration with Theoretical Physics division are presented in Paper 5. The accuracy of theoretical calculations depends on correct selection of exchange correlation functional and pseudopotentials. In Paper 5, the GGA approximation was used and resulted in a slight overestimation for predicted lattice constants. In Paper 4, ab initio calculations were used to investigate the phase stability of wurtzite, cubic, and hexagonal $\mathrm{Sc}_{\mathrm{x}} \mathrm{Al}_{1-\mathrm{x}} \mathrm{N}$ when in-plane lattice parameter is fixed.

\subsection{Phase stability predictions}

$\mathrm{Sc}_{\mathrm{x}} \mathrm{Al}_{1-\mathrm{x}} \mathrm{N}$ and $\mathrm{Y}_{\mathrm{x}} \mathrm{Al}_{1-\mathrm{x}} \mathrm{N}$ are called metastable materials because their mixing enthalpy $\Delta H_{m i x}$ (increase in the total energy of the system) is $>0$ and higher than for the binary $\mathrm{AlN}, \mathrm{ScN}$ and $\mathrm{YN}$ in their ground-state structures (wurtzite AlN, cubic ScN and cubic YN). Reactive sputtering allows synthesizing different alloys away from the thermodynamic equilibrium, so even metastable phases can be obtained. A metastable material also means that there is an internal driving force 
towards phase separation into domains with different crystal structures or compositions, e.g., into AlN-rich and ScN-rich or YN-rich domains, which can be controlled by adjusting the deposition parameters such as growth temperature (Paper 2).

Using $a b$ initio calculations mixing enthalpies vs. elemental concentrations in the alloy can be obtained for different crystal structures. An example is presented in Fig. 4.1 (adapted from Paper 5), where comparison between $\mathrm{Sc}_{\mathrm{x}} \mathrm{Al}_{1-\mathrm{x}} \mathrm{N}$ and $\mathrm{Y}_{\mathrm{x}} \mathrm{Al}_{1-\mathrm{x}} \mathrm{N}$ mixing enthalpies is presented. This graph tells us several things. Firstly, as expected, all investigated structures have positive $\Delta H_{m i x}$. Secondly, the wurtzite structure should dominate when $\mathrm{x}<0.75$, and afterwards the cubic structure would be more preferred. We can also see that the layered hexagonal structure is never the lowest in mixing enthalpy. These observations give a hint on what to expect when trying to produce $\mathrm{Y}_{\mathrm{x}} \mathrm{Al}_{1-\mathrm{x}} \mathrm{N}$ thin films in the deposition chamber. An initial experimental study, presented in Paper 5, shows that while at low Y concentrations the film is c-axis oriented wurtzite with some epitaxial relationship to the substrate, already at $\mathrm{x}=0.22$ the material becomes highly polycrystalline and without any preferred orientation.

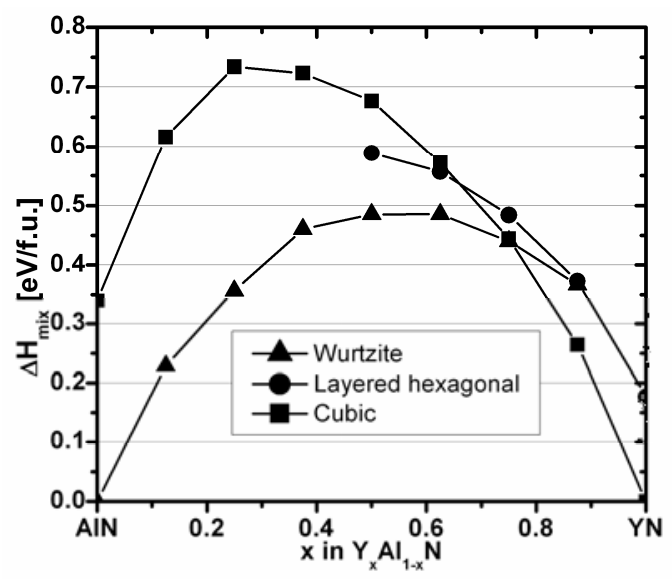

Figure 4.1. Mixing enthalpies for wurtzite, layered hexagonal and cubic $\mathrm{Y}_{\mathrm{x}} \mathrm{Al}_{1-\mathrm{x}} \mathrm{N}$. 


\subsubsection{Phase stability and lattice mismatch}

Due to the lattice mismatch between the film and the substrate, strain and stress can be present in the material, affecting the thin film growth, and phase stability, especially in the case of metastable ternaries such as $\mathrm{Sc}_{\mathrm{x}} \mathrm{Al}_{1-\mathrm{x}} \mathrm{N}$ [79]. $A b$ initio calculations can be used to investigate different conditions, such as tensile or compressive stress acting upon the material, and how it influences the phase stability. Such theoretical investigation is presented in Paper 4, where stress in $\mathrm{Sc}_{\mathrm{x}} \mathrm{Al}_{1-\mathrm{x}} \mathrm{N}(\mathrm{x}=0,0.125,0.25,0.375$, and 0.5$)$ was introduced by using a fixed inplane lattice parameter $a$ and allowing the material to relax in the out-of-plane direction. A compressive biaxial stress (positive lattice mismatch) was simulated by using the in-plane lattice parameter of $\operatorname{AlN} a_{\mathrm{AlN}}=3.1318 \AA$. The lattice matched case was achieved by $5 \%$ larger in-plane lattice parameter $a=3.2884 \AA$ representing $\mathrm{Sc}_{0.2} \mathrm{Al}_{0.8} \mathrm{~N}$. Finally, tensile biaxial stress (negative lattice mismatch) was introduced by using $10 \%$ larger in-plane parameter, $a=3.4450 \AA$. With the help of the internal parameter $u$ and $c / a$ ratio, the most stable phases were identified at each step. The $u$ is a dimensionless parameter defined as a ratio between the anion-cation (Al-N) bond length and the $c$ lattice parameter. In the case of an ideal wurtzite $u=3 / 8=0.375$, and $c / a=\sqrt{8 / 3}=1.633$, although experiments show these values for AlN to be slightly different: $u=0.38$ and $c / a=1.6$ [41]. For metastable layered hexagonal $\mathrm{ScN}, u=0.5$ and $c / \alpha \approx 1.27$ [34].

\subsection{Expected properties}

Apart from the preferred material phase and its stability, other physical properties of the materials can also be acquired from the theoretical calculations. In the scope of this thesis lattice constants and piezoelectric coefficients are of interest. Experimental and theoretically predicted lattice constants values of $\mathrm{Sc}_{\mathrm{x}} \mathrm{Al}_{1-\mathrm{x}} \mathrm{N}$ were presented by C. Höglund et al. in Ref. [5]. A similar study for $\mathrm{Y}_{\mathrm{x}} \mathrm{Al}_{1-\mathrm{x}} \mathrm{N}$ can be found in Paper 5. Calculations of the piezoelectric response $d_{33, f}$ for $\mathrm{Sc}_{\mathrm{x}} \mathrm{Al}_{1-\mathrm{x}} \mathrm{N}$, based on values from Ref. [34], and comparison with experimental data are presented in Paper 2. 


\section{Chapter 5}

\section{Characterization}

\subsection{Structural and mechanical properties}

\subsubsection{X-ray diffraction}

When X-rays interact with a solid material, they attenuate, are absorbed, or scattered. Elastic scattering of incoming photons upon collision with the inner shell electrons is the most important effect for x-ray diffraction (XRD): in the case of a crystalline material where the atoms are arranged in a periodic manner the constructive interference of x-rays leaving the sample in certain angles will form a diffraction pattern [43]. Bragg's law defines a relationship between the angle $\theta$ of the incident (and diffracted) beam and the atomic plane spacing $d$ (Fig. 5.1 (a)):

$$
n \cdot \lambda=2 \cdot d_{h k l} \cdot \sin \theta \text {, }
$$

where $\lambda$ is the $\mathrm{x}$-ray wavelength, $h k l$ are Miller indices defining the atomic plane and $n$ is an integer. For a hexagonal (wurtzite) crystal system, the following equation is valid:

$$
\frac{1}{d_{h k l}^{2}}=\frac{4}{3} \cdot \frac{h^{2}+h \cdot k+k^{2}}{a^{2}}+\frac{l^{2}}{c^{2}},
$$

where $a$ and $c$ are lattice constants. In the case of cubic crystal structure, where $a=c:$

$$
\frac{1}{d_{h k l}^{2}}=\frac{h^{2}+k^{2}+l^{2}}{a^{2}} .
$$


Because the wavelengths of x-rays are comparable to spacings between atoms, the diffracted beams, leaving at angles fulfilling Bragg's law, are of high intensity and are easy to detect. They are called Bragg reflections. This is the physical principle of the XRD - a non-destructive and versatile measurement technique used to evaluate crystalline materials.

(a)

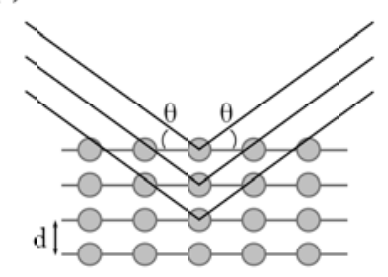

(b)

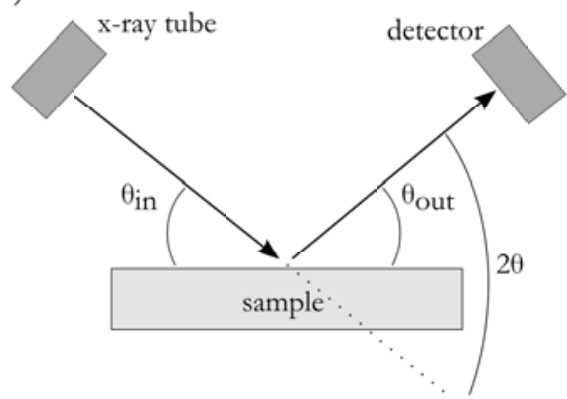

Figure 5.1. Principles of x-ray diffraction: (a) Bragg's law, (b) schematics of a Bragg-Brentano diffractometer.

In this thesis different XRD-based methods were employed to determine 1) crystal orientation, 2) crystalline quality, 3) phase and epitaxial relationship between the substrate and the film, 4) lattice constants, 5) film thickness, 6) reciprocal space maps, and 7) superlattice (SL) period:

1) One of the most common techniques is the symmetric $\theta / 2 \theta$ x-ray diffraction measurement, where the angle of the incident beam $\theta_{\text {in }}$ is the same the one of the diffracted beam $\theta_{\text {out }}$ (Fig. 5.1 (b)). Both angles are simultaneously changed in an angular region of interest to record Bragg reflections from atomic planes oriented parallel to the sample surface. An example of a $\theta / 2 \theta$ scan is Fig. 2 in Paper 1 where $\mathrm{XRD}$ was used to characterize $\mathrm{AlN}$ and $\mathrm{Sc}_{\mathrm{x}} \mathrm{Al}_{1-\mathrm{x}} \mathrm{N}$ thin films. The position of the peaks can be used to determine the crystalline phases, crystal lattice spacing in the direction perpendicular to the surface (the out-of-plane direction), and they also give information about the crystal orientation.

2) The intensity and the width of the peaks in the XRD spectra are used to evaluate the quality of the films. Narrow XRD peaks indicate a material with high 
crystalline quality. To get a quantitative estimation of the crystalline quality, a full width at half maximum (FWHM) value can be calculated from a so called " $\omega$ rocking curve" measurement around the selected peak position. In this type of measurement, the $2 \theta$ angular position is kept constant, while the incident beam angle $\omega$ is scanned in the range of $\Delta \omega$. The incidence angle in this kind of measurement is in general not equal to $2 \theta / 2$, and is therefore denoted $\omega$.

3) A symmetric $\theta / 2 \theta$ scan is limited to diffraction from atomic planes parallel to the sample surface. To determine the preferred orientation or epitaxial relationship between the substrate and the film, "pole figures" can be recorded. The measurement is performed at a fixed $2 \theta$ value while the intensity is measured when the angular orientation of the sample is changed through changing azimuth angle $\varphi$ and tilt angle $\psi$. In this way the orientations of the lattice planes corresponding to fixed $2 \theta$ are detected and can be shown in the pole figure as a function of $\varphi$ and $\psi$.

4) Peak positions in $\theta / 2 \theta$ scans can be used to extract the lattice constants. But if the film is $c$-axis oriented, only the $c$ parameter will be quantified. To obtain in-plane lattice constant, so called asymmetric XRD scans (where incoming beam angle is not the same as the reflected one) have to be performed to obtain reflections from inclined planes. In the case of $\mathrm{AlN}$, the $10 \overline{15}$ reflection is used quite often.

5) X-ray reflectivity (XRR) measurements can be used to determine the thickness of deposited films in the thickness range from 0.1 to $100 \mathrm{~nm}$ [80]. When working with ternary alloys the growth rate varies for different concentrations and different process pressures. The thickness measurements are very important in the electrical and optical characterization, where the film thickness is used for the calculations of relative dielectric constant $\mathcal{E}_{\mathrm{r}}$ (Section 5.3.2), or band gap determination (Section 5.3.1), so for accurate results and comparison it is best to have the same thicknesses for all samples in question. Though this measurement can be carried out with the same experimental setup as $\theta / 2 \theta$ measurements, this is 
not a diffraction technique, but instead is based on change in refractive index when x-rays pass from air into a solid material at $\theta$ values from $\sim 0.5^{\circ}$ to $\sim 5^{\circ}$. The intensity of the peaks depends on differences in electron density, while the distance between the peaks is material independent. An example of an XRR scan is shown in Fig 5.2. There are several different ways to extract thickness values from the recorded data. One of the simplest approximations, valid for low angles [22], is:

$$
\Delta \theta \approx \frac{\lambda}{n \cdot t}
$$

where $\lambda$ is the wavelength of x-rays, $\Delta \theta=\theta_{m+n}-\theta_{m}$ is the angle difference between peak positions of the Kiessig fringes in radians, $n$ is the number of fringes between $\theta_{\mathrm{m}+\mathrm{n}}$ and $\theta_{\mathrm{m}}$, and $t$ is the thickness of the film.

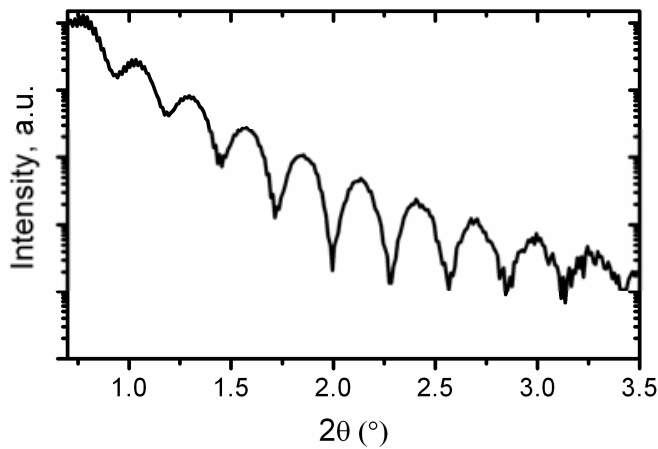

Figure 5.2. An XRR scan of AlN film. Using the eq. (5.4) the thickness was determined to be $\mathrm{t}=320 \AA$, using the eq. (5.5) $\mathrm{t}=319 \AA$, and fitting the data in WinGixa software resulted in $\mathrm{t}=306 \AA$.

Due to refraction effects, equation (5.4) becomes less accurate when using fringe positions at low incidence angles. For more accurate results, other methods are recommended, such as plotting $\sin ^{2} \theta$ against $\mathrm{n}^{2}$ based on the modified Bragg's law:

$$
n \cdot \lambda=2 \cdot t \cdot \sin \theta \sqrt{1+\frac{\eta^{2}-1}{\sin ^{2} \theta}},
$$

where $n$ is a number of a peak, and $\eta$ is a complex refractive index of the film. The slope of the plotted line is equal to the film thickness $t$. As the XRR data can be influenced by density and surface roughness of the films, it is also recommended to 
use fitting software, such as WinGixa, for additional accuracy and information about the material. In my experience, the difference between the manual calculations and the simulations increases with thickness of the analyzed thin film.

6) Reciprocal space map (RSM) is a two-dimensional map composed of series of $2 \theta / \omega$ scans separated by small offset of $\omega$. It is used to map out different reciprocal lattice points $(\mathrm{RLP})$. In the reciprocal lattice, each lattice point represents a set of lattice planes in the real space. Such measurements can be used, for example, to extract the lattice parameters, or to identify different crystalline phases. RSM of asymmetric $10 \overline{15}$ reflection in $\mathrm{Sc}_{\mathrm{x}} \mathrm{Al}_{1-\mathrm{x}} \mathrm{N} / \mathrm{In}_{\mathrm{y}} \mathrm{Al}_{1-\mathrm{y}} \mathrm{N}$ superlattices was recorded and is shown in Paper 4. Usually the maps are plotted in reciprocal space coordinates $Q_{\mathrm{x}}$ and $Q_{\mathrm{z}}$. If Miller's indices of the observed reflections are known, the lattice parameters of a wurtzite (hexagonal) material can be extracted using the following expressions:

$$
c=l \frac{2 \pi}{Q_{z}}, \quad a=\frac{2 \pi}{Q_{x}} \sqrt{\frac{4}{3}\left(h^{2}+k^{2}+h k\right)},
$$

where $Q_{\mathrm{x}}$ and $Q_{\mathrm{z}}$ can be expressed with reference to angular positions [43]:

$$
\begin{aligned}
& Q_{x}=\frac{2 \pi}{\lambda}(\cos (\theta-\omega)-\cos (\theta+\omega)) \\
& Q_{z}=\frac{2 \pi}{\lambda}(\sin (\theta-\omega)+\sin (\theta+\omega))
\end{aligned},
$$

where $K=2 \Pi / \lambda$ is the magnitude of the x-ray wave vector, and accessible region for data collection is $-2 K \leq Q_{\mathrm{x}} \leq 2 K$ and $0 \leq Q_{\mathrm{z}} \leq 2 K$.

In a RSM, certain features will be visible due to different crystal imperfections. They can be used to gather more information about the samples. For example, so called mosaicity - the spread of the RLP in the $\omega$ direction - is caused by slight misorientation of lattice plains or grains. Spread in $2 \theta / \omega$ direction can be related to composition, and a shift of the RLP that does not match any of the $\omega$ or $2 \theta / \omega$ scan directions usually is caused by strain, while a spread in such direction can be caused by features in the sample appearing at certain crystallographic planes. 
7) XRD patterns of SL structures have special features called "superlattice satellites" which surround an "average (Bragg) peak". The latter is caused by interference between the diffraction by the crystal lattices in each of materials $\mathrm{A}$ and $\mathrm{B}$, and corresponds to a weighted average of the lattice parameters in the SL, or in some cases - average composition of the SL. The satellites are present when there is a periodic repetition of a certain sequence of layers and when there exists a degree of coherence between the crystal lattices in adjacent layers of the same kind. The satellites suround the average Bragg peak and are denoted by integers $\pm n$, representing the order of each satellite at lower and higher angles than the Bragg peak which is assigned $n=0$. The distances between the satellite peaks can be used to calculate the superlattice period $\Lambda$ using the following expression:

$$
\Lambda=\frac{\lambda\left(n_{1}-n_{2}\right)}{2 \cdot\left(\sin \theta_{n_{1}}-\sin \theta_{n_{2}}\right)} .
$$

Here, $\lambda$ is characteristic X-ray wavelength, in the case of $\mathrm{Cu} \mathrm{Ka} a_{1+} \mathrm{a}_{2}$ it is $1.5418 \AA$, $n_{1}$ and $n_{2}$ are the orders of two arbitrary satellites, and $\theta_{\mathrm{n} 1}$ and $\theta_{\mathrm{n} 2}$ are their angular positions, respectively. This method was used to calculate the superlattice period in Paper 4.

Of course, in reality, the crystal structure of a thin film is seldom perfect. There are many different factors, for example, grain size or defects that can influence the height, the shape and the width of the peaks. Strain and stress in the film affects the lattice constants causing the shift in the XRD peak positions. In the case of thickness measurements, surface roughness and density of the film also contribute to the end result.

\subsubsection{Transmission electron microscopy}

The idea of a transmission electron microscope (TEM) was first proposed and the term was first used in 1932 by Knoll and Ruska, who later received a Nobel Prize for it [81]. The main motivation was to improve the imaging resolution which in the ordinary visible-light microscopes is limited by the wavelength of visible light to $300 \mathrm{~nm}$. The theoretical resolution limit for TEM using, for example, $100 \mathrm{keV}$ electrons is $4 \mathrm{pm}$ [81]. In reality, the resolution is limited by imperfect 
electron lenses and other instrument-related issues and is of the order of $1 \AA$. Depending on the operation mode, TEM makes it possible to obtain bright field (BF), dark field (DF), or atomic-resolution images (high resolution TEM, (HRTEM)), diffraction patterns from nanometer-scale regions (selected area electron diffraction (SAED) pattern), and spectroscopic information (scanning TEM or STEM coupled with energy dispersive x-ray spectroscopy or EDX). All these data are especially important when dealing with metastable phases and piezoelectric materials, where microstructure and crystalline quality have influence on other properties.

The principle of operation of the TEM is based on electrons accelerated by typically $200 \mathrm{kV}$ potential and then focused using multiple electromagnetic lenses onto a very thin "electron-transparent" sample. When electrons travel through the sample, they can be transmitted or scattered. The transmitted and scattered electrons are focused again and projected onto a screen, where an image is formed (Fig. 5.3). The scattered electrons can be used to obtain additional information about the sample, for example chemical composition.

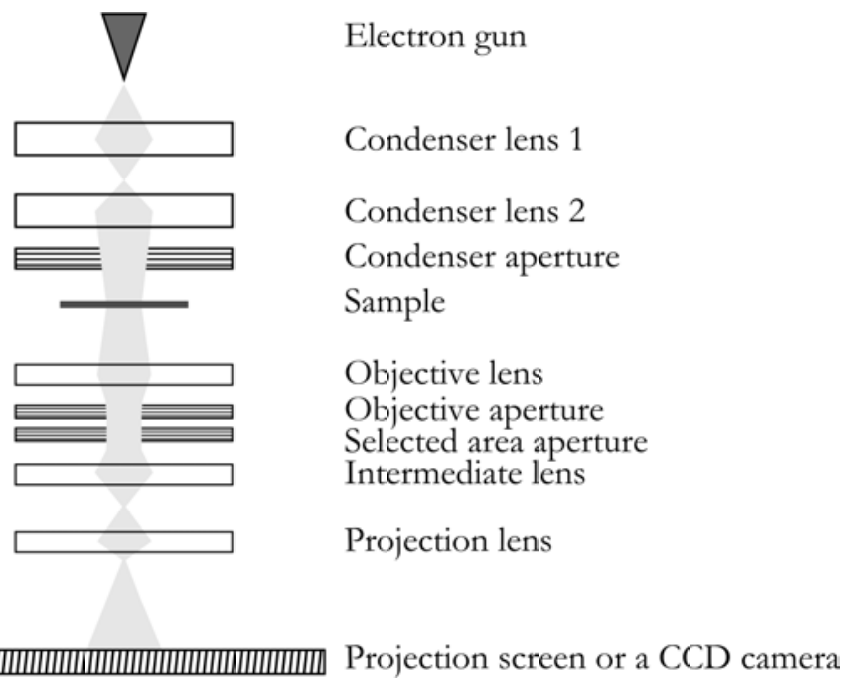

\section{पाm}

Figure 5.3. A schematic drawing of a basic transmission electron microscope. 
Though supplying us with a lot of valuable information, TEM also has its drawbacks - complicated and destructive sample preparation, small sampling volume and the interpretation of results is not trivial.

In Figure 5.4 examples of images obtained with different operation modes are shown. By inserting an objective aperture or a selected area aperture (Fig 5.3) and by adjusting the strength of the intermediate lens one can switch between imaging and diffraction modes:

1) In the BF imaging mode, only the central transmitted beam is selected with the objective aperture, and the contrast is formed by mass-thickness and diffraction. Darker areas represent better crystallinity, thicker sample, and higher electron density, that indicates a presence of heavier atoms (Fig. 5.4 (a)).

2) In the DF mode the aperture is displaced so the central beam is blocked and the off-axis scattered (diffracted) beams can pass through. This way the most intensity comes from grains that have most defects or that are most misaligned, while voids and highly crystalline grains become dark (Fig. 5.4 (b)).

3) Lattice resolved images can be obtained as a result of the phase contrast present at high magnification in HRTEM mode (Fig. 5.4 (c)). HRTEM micrographs are used for analysis of the crystal structure, grain boundaries, interfaces, stacking faults and other defects. The interpretation of phase contrast images is challenging since not only the sample structure, but also imaging conditions (defocus, astigmatism) affect the final image. Examples of HRTEM image analysis can be found in Paper 2 and Paper 4.

4) If, instead of the objective aperture a selected area aperture is inserted and the strength of the intermediate lens is adjusted, a SAED pattern is projected onto the screen. In this mode it is possible to move the beam around the sample to obtain a diffraction pattern from different areas, for example, if one wants to exclude diffraction spots from the substrate. In Fig. 5.4 (d) a pattern with spots originating from the substrate, seed layer and film is shown. Spot broadening 
indicates degradation in crystalline quality, and for a completely polycrystalline material the diffraction pattern would consist of rings instead. More indexed SAED patterns and descriptions of different features can be found in Paper 2 and Paper 5.

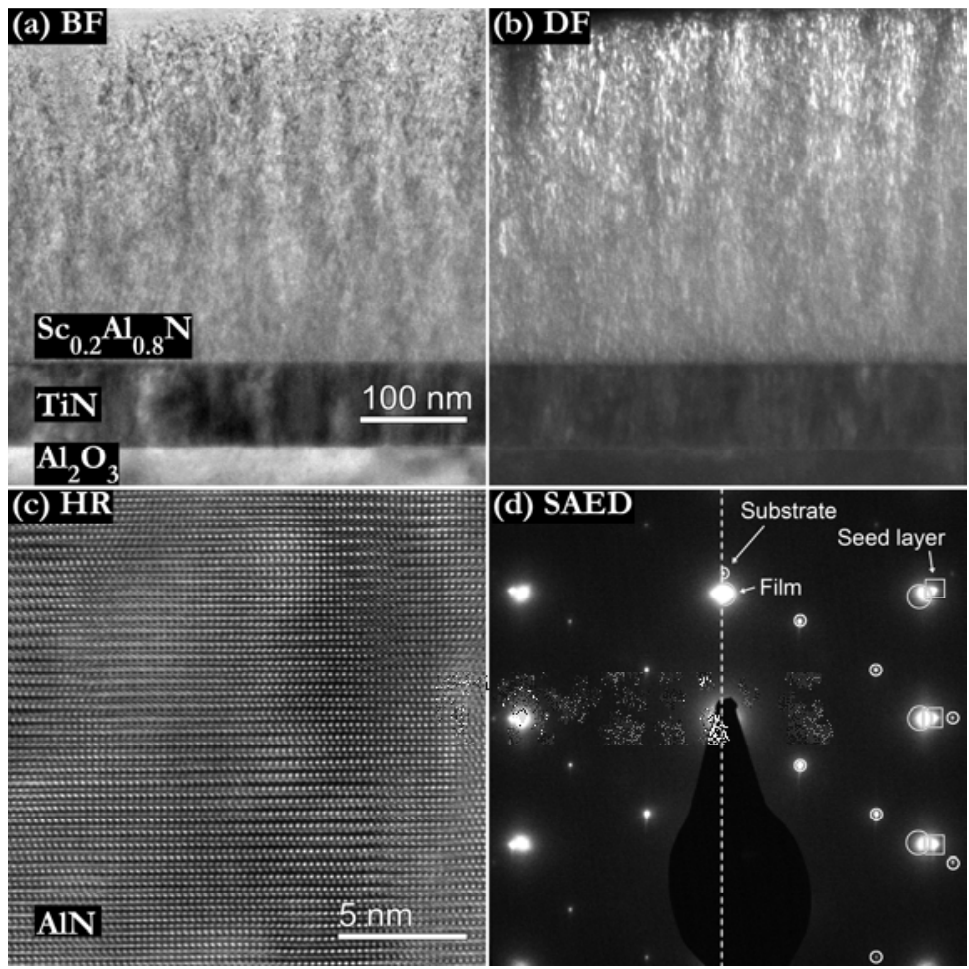

Figure 5.4. Images obtained using different operation modes of TEM: a) bright field and b) dark field overview images of $\mathrm{Sc}_{0.2} \mathrm{Al}_{0.8} \mathrm{~N}\left(\mathrm{~T}_{\mathrm{s}}=800{ }^{\circ} \mathrm{C}\right)$, c) high resolution image of AlN with [2 $\overline{1} \overline{1} 0$ ] zone axis, d) selected area diffraction pattern of a $\mathrm{Sc}_{0.2} \mathrm{Al}_{0.8} \mathrm{~N}\left(\mathrm{~T}_{\mathrm{s}}=400{ }^{\circ} \mathrm{C}\right)$, with $\mathrm{Al}_{2} \mathrm{O}_{3}$ substrate, $\mathrm{TiN}$ seed layer and film diffraction spots marked.

5) STEM is a rather different TEM technique in the sense that a very narrow probe-like beam is used and the sample is scanned point by point. The high angle annular dark field (HAADF) detector can be used together with STEM to obtain information only from electrons scattered in certain angles. The intensity in HDAADF-STEM images depends on the atomic mass and the sample thickness. The sample areas composed of lighter elements will appear darker, as will the thinner regions. When STEM is combined with EDX, an elemental map of sample areas can be obtained, for example, see Fig. 5 in Paper 2, or Fig. 3 in Paper 4. 


\subsubsection{Atomic force microscopy}

Atomic force microscopy (AFM) is a scanning probe microscopy (SPM) technique used for surface topography analysis. It was developed in 1986 as collaboration between Stanford University and IBM by Binning, Quate, and Gerber. In AFM, the sample surface (or rather the adsorbed fluid layer) is probed with a sharp tip located on an end of a cantilever. The cantilever is bent or deflected by forces between the sample and the tip. The deflections are measured by a $2 \mathrm{D}$ photodetector using a reflected laser beam. The information is then used by special software to generate a topographic 3D map of the sample surface. Depending on the distance between the tip and the sample, operation modes can be divided into three groups: a) contact mode, b) intermittent (tapping) mode, and c) non-contact mode. In my studies, tapping mode AFM was used for analysis of surface roughness, while piezoresponse force microscopy (PFM, see Section 5.3.3) was performed in contact mode.
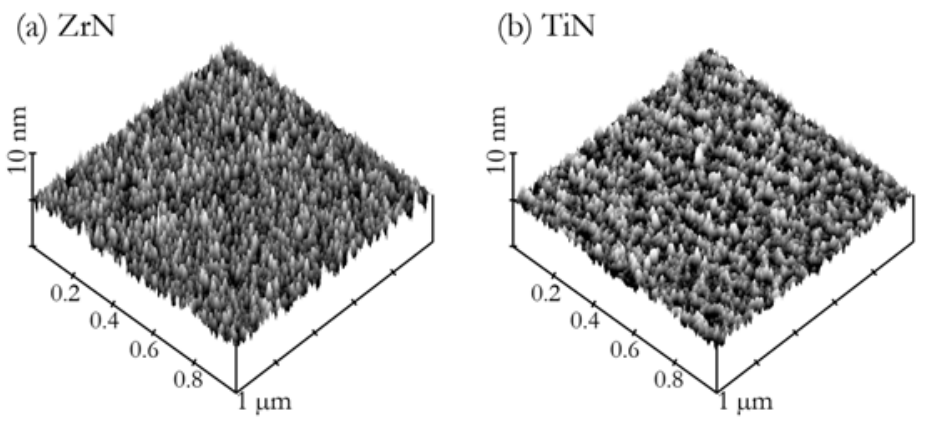

Figure 5.5. Surface topography of different seed layers: (a) ZrN, (b) TiN.

In tapping mode, the cantilever is oscillated at its resonance frequency, which is material as well as cantilever-dimension dependent. The amplitude can range from $20 \mathrm{~nm}$ to $100 \mathrm{~nm}$, and at each swing the tip lightly taps the sample surface. A feedback loop ensures a constant amplitude mode.

An example is shown in Fig. 5.5. In Paper 2, where test series were carried out with an alternative seed layer - $\mathrm{ZrN}$, providing a better lattice match for $\mathrm{Sc}_{\mathrm{x}} \mathrm{Al}_{1-\mathrm{x}} \mathrm{N}$ samples with higher $\mathrm{Sc}$ content. The expected improvement in crystalline quality was not observed, one of possible reasons could be a different 
surface topography. This technique was also used to evaluate surface roughness of $\mathrm{Y}_{\mathrm{x}} \mathrm{Al}_{1-\mathrm{x}} \mathrm{N}$ thin films in Paper 5-6.

The main advantages of the tapping mode AFM are lower damage possibility for both the sample and the tip compared to contact mode, as well as better accuracy for large scan sizes compared to non-contact mode [82].

\subsubsection{Nanoindentation}

Nanoindentation is mainly used for determination of hardness, elastic modulus, and other mechanical properties such as friction and wear. However, it can also be used for electrical and piezoelectric characterization. One particular application of interest to my research is piezoelectric nanoindentation, described in more detail in Section 5.3.4. The main principle of the nanoindentation technique is making an indentation on the scale of nanometers with a special tip and recording the load-displacement curve. The indenter tip can be spherical, flat, or sharp, for example a conical or a three-sided Berkovich tip. A typical loadingunloading curve from a $\mathrm{Sc}_{0.3} \mathrm{Al}_{0.7} \mathrm{~N}$ sample is displayed in Fig. 5.6. Here, the load $P$ is slowly increased up to $P_{\max }$ and at each step the displacement $h$, i.e., the depth of penetration, is recorded. The unloading path is different due to the plastic deformation occurring in the material. In Fig $5.6 h_{\mathrm{p}}$ is the residual penetration depth caused by the plastic deformation, and $h_{\mathrm{e}}=h_{\max }-h_{\mathrm{p}}$ is the elastic penetration depth which is recovered upon the unloading. Hardness $H$, usually expressed in GPa, is defined as a ratio between the load $P$ and the contact area $A$ :

$$
H=\frac{P}{A}
$$

The slope $S$ together with maximum displacement $h_{\max }$ can be used to obtain the reduced (combined) elastic modulus $E^{*}[83]$ :

$$
S=\left.\frac{d P}{d h}\right|_{h_{\max }}=2 \beta E * \sqrt{\frac{A}{\pi}}
$$

Here in the case of a Berkovich tip 1.0226 $\leq \beta \leq 1.085$ is a dimensionless correction fitting parameter [84]. The actual elastic modulus of the indented material can be extracted if the Poisson ratio and the Young's modulus of the indenter are known. 


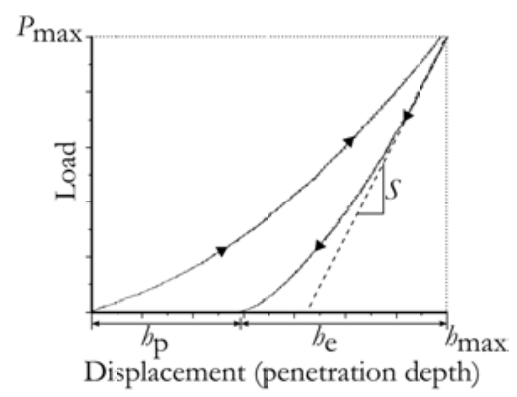

Figure 5.6. Load-displacement curve recorded during the nanoindentation of $\mathrm{Sc}_{0.3} \mathrm{Al}_{0.7} \mathrm{~N}$.

This measurement can be done both in bulk material and thin films. However, it should be noted that if the penetration depth is higher than $10 \%$ of thin film thickness the substrate can also influence the recorded data. The solution would be to either test thicker films or to limit the penetration depth by using smaller load.

\subsection{Chemical composition}

\subsubsection{Rutherford backscattering spectrometry}

Rutherford Backscattering Spectrometry (RBS) is a quantitative technique used for composition analysis of thin films, especially useful when dealing with heavy elements. RBS is based on the backscattering phenomenon when a light ion, for example $\mathrm{He}^{+}$, is elastically backscattered from heavier atoms in the sample. Depending on the atomic mass of the encountered atom and how deep in the sample it is located, the incoming ion (also known as projectile) would lose a certain amount of energy:

$$
E_{1}=E_{0} \cdot K_{\text {proj }},
$$

here $\mathrm{E}_{0}$ is the energy of the incoming ion, $E_{1}$ - of the backscattered ion, and $K_{\text {proj }}$ is so called kinematic factor that depends on atomic mass of incoming ion and atom of the sample it backscatters from:

$$
K_{p r o j}=\left[\frac{\sqrt{M_{2}^{2}-M_{1}^{2} \cdot \sin ^{2}(\theta)}+M_{1} \cdot \cos (\theta)}{M_{1}+M_{2}}\right]^{2}=\left(\frac{M_{2}-M_{1}}{M_{2}+M_{1}}\right)^{2}
$$


if $\theta=180^{\circ}$, which is a preferred position for the detector, although in practice the value of $\theta$ is closer to $170^{\circ} . K_{\text {proj }}$ is always less than 1 .

(a)

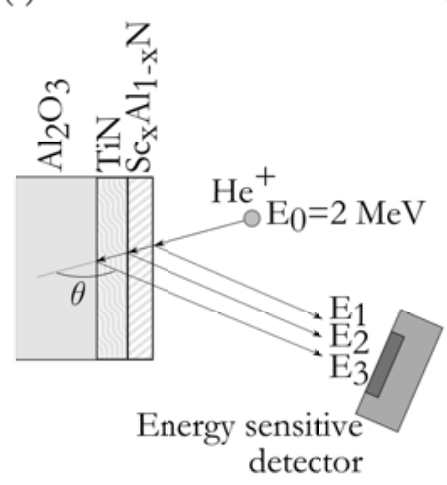

(b)

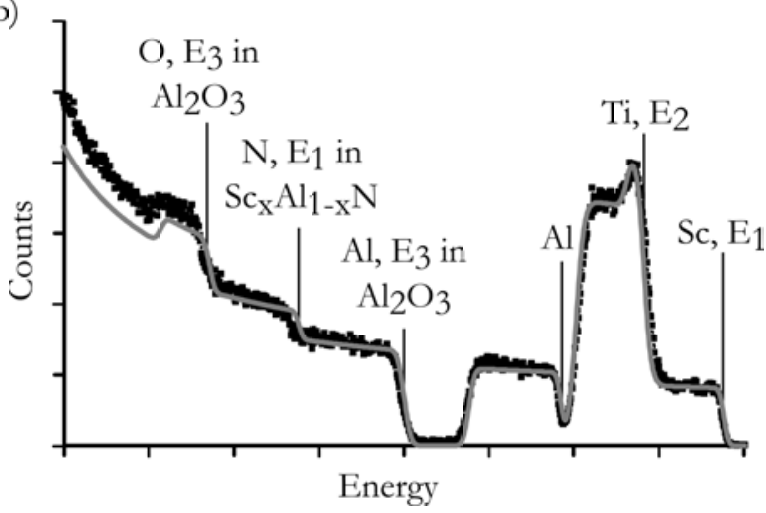

Figure 5.7. Rutherford Backscattering Spectroscopy: a) measurement geometry, b) experimental (black dots) and simulated (grey line) results.

The maximum sampling depth that can be reached with this method is $\sim 500 \mathrm{~nm}$. The energy of backscattered ions is measured with an energy sensitive detector, used to record a spectrum with number of counts per energy channel. The recorded data is then compared to a simulated back-scattered spectrum using special software, for example SIMNRA. An example of the measurement geometry with incident ions of $2 \mathrm{MeV} \mathrm{He}^{+}$along with an obtained RBS spectrum for a ScAlN/TiN/Al $\mathrm{O}_{2} \mathrm{O}_{3}$ sample is shown in Fig. 5.7 (a) and (b), respectively. The solid line represents the simulated data and the scatter - experimental results. From the intensity of the peaks the composition of this particular sample was found to be $\mathrm{Sc}_{0.22} \mathrm{Al}_{0.78} \mathrm{~N}$ with a $\mathrm{Ti}_{0.49} \mathrm{~N}_{0.51}$ seed layer.

Despite the fact that mass resolution is better for lighter elements, usually signals from light elements overlap with the substrate and become difficult to analyze. Therefore, in practice, RBS is employed mostly for the analysis of heavy target elements deposited on substrates made from light elements and other techniques should be used in combination with RBS to obtain more detailed information. 


\subsubsection{Elastic recoil detection analysis}

When working with group III materials, contaminants such as oxygen have a strong influence on piezoelectric and electrical properties of the films [63]. Time of flight energy elastic recoil detection analysis (ToF-E ERDA) is another ion-beam based characterization technique used for determining the chemical composition of thin films. The main advantage of this technique is its sensitivity to light elements, as well as the ability to produce a depth profile.

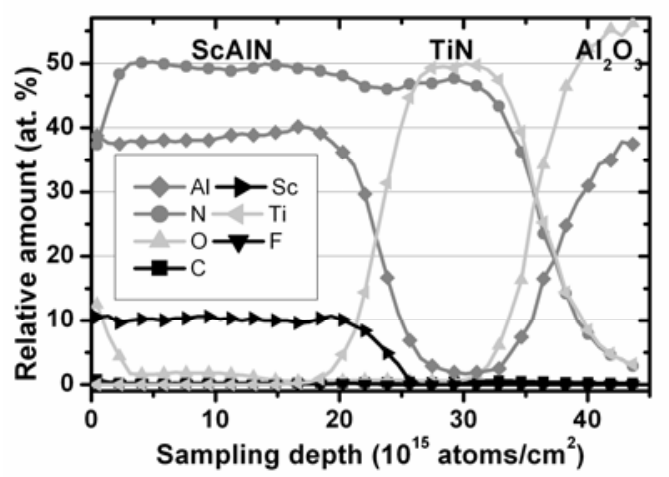

Figure 5.8. A typical ERDA depth profile of the $\mathrm{Sc}_{\mathrm{x}} \mathrm{Al}_{1-\mathrm{x}} \mathrm{N} / \mathrm{TiN} / \mathrm{Al}_{2} \mathrm{O}_{3}$ structure studied in Paper 2.

Similarly to RBS, the sample is irradiated with an ion beam, but in the case of ERDA, the ions are heavier than the target elements in the sample, for example ${ }^{127} \mathrm{I}^{9+}$, and have much higher energy $(10-100 \mathrm{MeV})$. Another difference is that while in RBS the back-scattered ions are detected, in ERDA the target atoms are kicked out by heavier ions and leave the sample in the forward direction $\left(0^{\circ}<\theta<90^{\circ}\right)$. By combining time of flight information together with the energy measurement the mass of the recoiled atom is measured and depth profiling is acquired [85].

For the same sample as in section 5.2.1, the composition inside the film was found to be $\mathrm{Sc}_{0.21} \mathrm{Al}_{0.77} \mathrm{~N}_{0.988}\left(\mathrm{~F}_{0.002} \mathrm{O}_{0.034} \mathrm{C}_{0.0034}\right)$, see Fig. 5.8.

As mentioned in section 3.4, the elemental Y target contained unexpectedly high amounts of $\mathrm{O}$ and $\mathrm{F}$. By using ERDA it was possible to quantify the amounts of these elements in the films and their nearly-linear dependence on Y magnetron power suggests that the $\mathrm{Y}$ target was the main origin of the contamination. 


\subsection{Optical, electrical, and piezoelectrical properties}

\subsubsection{Spectroscopic ellipsometry}

Spectroscopic ellipsometry (SE) is a non-destructive and contactless optical technique that accurately determines the dielectric constants and thickness of the individual layers in a multilayered sample or in bulk. In SE a change of light polarization upon reflection/transmittance from the sample is measured. In my research, $\mathrm{SE}$ was employed to determine the high frequency dielectric constants of $\mathrm{Sc}_{\mathrm{x}} \mathrm{Al}_{1-\mathrm{x}} \mathrm{N}$ (Paper 1), as well as the band gap energy (Paper 5) and the optical constants of $\mathrm{Y}_{\mathrm{X}} \mathrm{Al}_{1-\mathrm{X}} \mathrm{N}$ (Paper 6).

(a) Variable angle spectroscopic ellipsometer

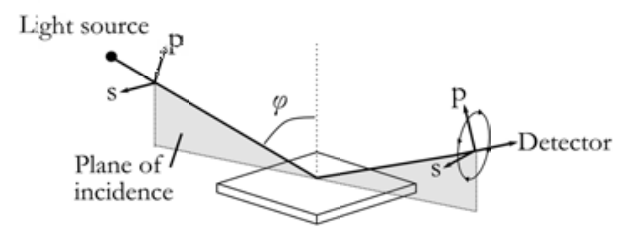

(b) Polarization ellipse

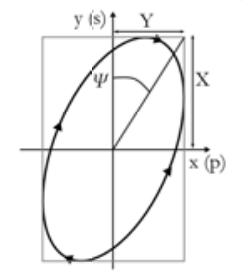

Figure 5.9. (a) A schematic layout of a variable angle spectroscopic ellipsometer, and (b) polarization ellipse of the light leaving the sample.

In SE, the sample is irradiated by a light source with a known polarization and the change of polarization of the reflected light is measured over a specific energy (wavelength) range. A schematic drawing is shown in Fig. 5.9 (a). The term "ellipsometry" comes from the analysis of the polarization state of the reflected light wave, which is generally elliptic, as shown in Fig. 5.10 (b). SE determines the complex reflectance ratio $\rho$ defined in terms of the standard ellipsometric parameters $\psi$ and $\Delta$ as:

$$
\rho=\frac{r_{p}}{r_{s}}=e^{i \Delta} \tan \psi,
$$

here $r_{p}$ and $r_{s}$ are the reflection coefficients for parallel $(p)$ and perpendicular $(s)$ polarized light (Fig. 5.9(a)), respectively. The absolute value of the complex ratio is defined as $\tan \psi=X / Y$, and $\Delta$ is a relative phase change of the electric field vector components $p$ and $s$ upon interaction with the sample (Fig. 5.9 (b)) and ranges from $-\Pi$ to $+\Pi$ [86]. Largest changes in polarization occur at oblique angles, 
typically between $50^{\circ}$ and $75^{\circ}$. In order to improve the accuracy of the results, $\psi$ and $\Delta$ can be recorded as a function of angle of incidence, as it was done in Paper 5 and Paper 6 .

Ellipsometry is an indirect technique, which means that an optical model is required to determine the sample properties. In the case of a thin film an optical structure model has to include the substrate, seed layer, film, capping layer, and so on, where each component is defined by its optical constants and layer thickness. Afterwards, the fitting of the parameterized optical model to experimental data ( $\psi$ and $\Delta$ ) is performed in order to obtain the physical properties and parameters of each constituent of interest.

The SE measurements can be performed in different energy ranges from infrared (IR) to ultraviolet (UV). In the case of $\mathrm{Y}_{\mathrm{x}} \mathrm{Al}_{1-\mathrm{x}} \mathrm{N}$, the measurements were performed in near-IR-UV range (1-6.5 eV). An example of IR measurements $(0.18-0.7 \mathrm{eV})$ can be found in another publication about $\mathrm{Y}_{\mathrm{x}} \mathrm{Al}_{1-\mathrm{x}} \mathrm{N}$ thin films (not included in this thesis), where the phonon (a quantum of lattice vibrations) behavior as a function of yttrium concentration is investigated [87].

\subsubsection{Electrical characterization}

Electrical characterization is a very important part of investing a potentially piezoelectric material. Dielectric constant, electromechanical coupling coefficient, leakage currents, and losses (dissipation) can be evaluated using current-voltage (I-V) and capacitance-voltage $(\mathrm{C}-\mathrm{V})$ measurements.

$\mathrm{Au} / \mathrm{Cr} / \mathrm{Sc}_{\mathrm{x}} \mathrm{Al}_{1-\mathrm{x}} \mathrm{N} / \mathrm{TiN} / \mathrm{Al}_{2} \mathrm{O}_{3}$ structures, shown in Fig. 5.10, were used to determine how alloying affects the dielectric properties of the films. C-V measurements are performed by applying a DC bias voltage to the structure while making the measurements with an AC signal. The DC voltage is increased stepwise, the AC sweep is performed at each step and the capacitance $\mathrm{C}$ is measured. Usually such measurements are performed at an AC frequency in the range of $10 \mathrm{kHz}-10 \mathrm{MHz}$. For the measurements presented in Paper 1 and Paper 2 the DC voltage was changed from $-5 \mathrm{~V}$ to $5 \mathrm{~V}$ by $1 \mathrm{~V}$ steps with $\mathrm{AC}$ amplitude of $100 \mathrm{mV}$ at $1 \mathrm{MHz}$. Measurements can be repeated at different frequencies to ensure the stability of a device. 


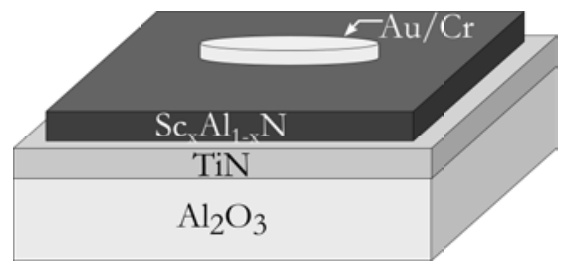

Figure 5.10. A schematic layout of structures with a $100 \mathrm{~nm}$ thick TiN bottom electrode and a $\mathrm{Au} / \mathrm{Cr}$ top electrode, $600 \mu \mathrm{m}$ in diameter, used in the electrical characterization.

For a perfect dielectric material, the result of $\mathrm{C}-\mathrm{V}$ measurement would be a straight horizontal line - constant capacitance at each step of voltage, though in reality there usually is a slight slope. From the $\mathrm{C}-\mathrm{V}$ measurement, the relative dielectric constant $\mathcal{E}_{\mathrm{r}}=\mathcal{\varepsilon} / \mathcal{E}_{0}$ can be extracted:

$$
C=\frac{\varepsilon \cdot A}{d}=\frac{\varepsilon_{r} \cdot \varepsilon_{0} \cdot A}{d}
$$

where $\mathrm{A}$ is the area of the capacitor and $\mathrm{d}$ is the thickness of a dielectric material between the plates (electrodes). In the case of structures shown in Fig. 5.8, the capacitor area was defined by the size of top electrode. The resulting dielectric constants are presented in Paper 1.

As mentioned above, another material property that can be obtained from such measurements is electromechanical coupling $k_{\mathrm{t}}{ }^{2}$. It is the ratio between electrical energy converted to mechanical energy and input electrical energy, or mechanical energy converted to electric energy and input mechanical energy [10], so in effect it is an efficiency of energy conversion in a piezoelectric material. Typical values found in literature for AlN are $7 \%$. Using the following equation, the electromechanical coupling for $\mathrm{Sc}_{\mathrm{x}} \mathrm{Al}_{1-\mathrm{x}} \mathrm{N}$ films was shown to increase up to $10 \%$ with $\mathrm{x}=0.2($ Paper 1$)$ :

$$
k_{t}^{2}=\frac{100 \cdot e_{33}{ }^{2}}{C_{33} \cdot \varepsilon_{33}},
$$

here $e_{33}$ is the piezoelectric constant, $C_{33}$ is stiffness, and $\varepsilon_{33}$ is the dielectric constant of the material.

If current is measured as a function of applied voltage, a current-voltage (I-V) characteristic can be obtained. For a good dielectric (insulating) material, the 
resulting plot should be a horizontal line at $I=0 \mathrm{~A}$ meaning that there was no current flowing between the electrodes. In reality the line is slightly tilted. This measurement can be used to determine if there are any leakage currents; in this case the current should increase with every step of the voltage. Such measurements were performed on the structures shown in Fig. 5.10 and the results are presented in Paper 2, Figure 6. In those $\mathrm{Sc}_{\mathrm{x}} \mathrm{Al}_{1-\mathrm{x}} \mathrm{N}$ samples the leakage current was increasing with increasing Sc concentration as well as with increasing growth temperature.

\subsubsection{Piezoresponse force microscopy}

Piezoresponse force microscopy (PFM) is another SPM technique. In general, it is rather similar to AFM (Section 5.1.3). The main difference is that in PFM the converse piezoelectric effect is used; an electric field is applied across the sample through a conductive tip. This causes an expansion or contraction of the material leading to surface vibrations. This way, instead of topography, a piezoresponse map is formed. The measurements are carried out in contact mode. The phase contrast of maximum $180^{\circ}$ can be obtained if two domains are oriented normal to the sample surface but with the opposite polarity. Figure 5.11 is an example of such mapping done on two different samples. The phase polarity distribution in the $\mathrm{Sc}_{\mathrm{x}} \mathrm{Al}_{1-\mathrm{x}} \mathrm{N}$ sample in Fig. 5.11(a) seems to be rather uniform, while another $\mathrm{Sc}_{\mathrm{x}} \mathrm{Al}_{1-\mathrm{x}} \mathrm{N}$ sample (Fig. 5.11(b)) shows several distinctive areas where the phase is different than film average (bright and dark spots). It was later discovered that this particular $\mathrm{Sc}_{\mathrm{x}} \mathrm{Al}_{1-\mathrm{x}} \mathrm{N}$ sample had oxygen content of $>1$ at.\%. Data in the literature shows that oxygen contamination usually has a detrimental effect on piezoelectric response and can cause a sudden change in polarity [63], which could explain the presence of such areas.

While the PFM is very useful for verification of uniform polarization in the sample, the extraction of actual piezoelectric constants is complicated because a system-inherent background level is always present, as well as an electrostatic contribution from the surface charges. Also, the output signal is usually rather noisy. If an $\mathrm{AC}$ modulation voltage $V=V_{0} \cdot \cos \omega t$ is applied and the surface displacement $\Delta \boldsymbol{Z}$ is measured through a standard lock-in amplifier set up, a 
following expression can be used for the extraction of effective piezoelectric response $d_{33, e f f}$.

$$
\Delta Z=\Delta Z_{0} \cdot \cos (\omega t+\varphi) .
$$

Here, $\Delta Z_{0}=d_{33, \text { eff }} \cdot V_{0}$ is the amplitude and $\varphi$ is the phase difference between the voltage and the piezoresponse [88]. A more detailed review of this technique and recommended experimental parameters can be found in Ref. [89]. Piezoelectric response values obtained by PFM and their comparison to theoretical calculations and results acquired from double beam interferometry (DBI) technique (Section 5.3.4) are presented in Paper 2. PFM mapping was used in Paper 3 to ensure that the samples were uniform with respect to piezoelectric phase.
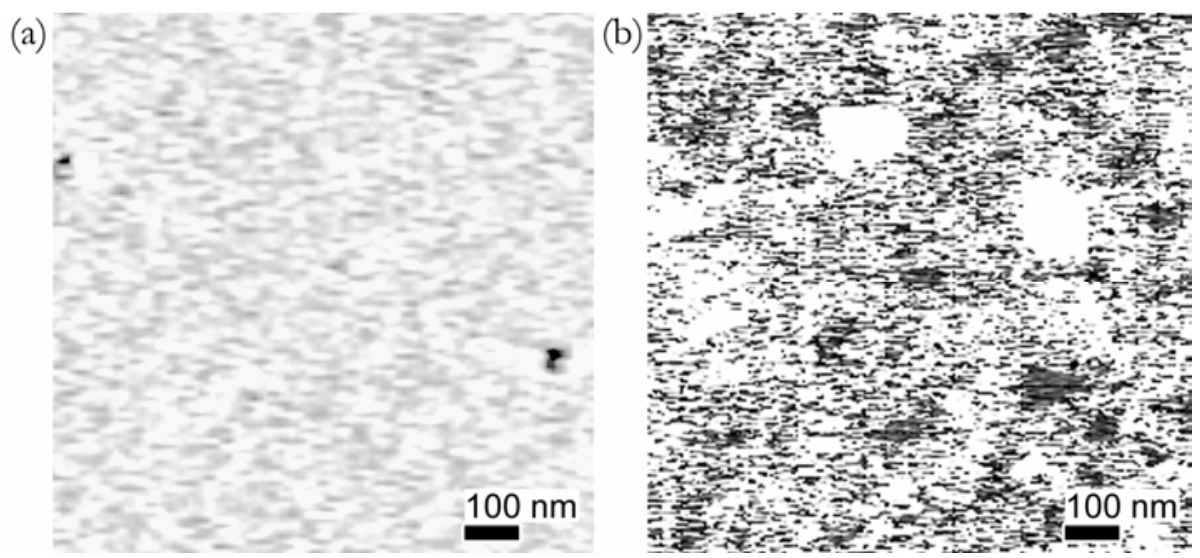

Figure 5.11. Phase images obtained by PFM: (a) good quality ScAlN and (b) ScAlN with elevated oxygen content.

\subsubsection{Piezoelectric nanoindentation}

As mentioned in Section 5.1.4, the nanoindentation can be used for electrical and piezoelectrical characterization. In piezoelectric nanoindentation (PNI) the nanoindentation experiments are performed with a conductive tip, for example boron-doped diamond. By applying a voltage through the tip or through the bottom electrode in the sample, the surface displacement can be recorded with the tip, in a similar way as PFM [90]. Both DC and AC bias voltage can be used. However, PFM is a surface sensitive technique and limited to very small loads, so the direct piezoelectric effect cannot be observed. Additionally, using the nanoindenter, the 
measurement of a direct piezoelectric effect is possible by indenting the film and measuring the generated voltage as a function of load [91,92]. However, when comparing materials of different hardness, voltage versus load can be misleading: softer material will be deformed more at the same load, causing higher generated voltage. Instead, load versus displacement should be used. Both nanoindentationbased methods - the DC PNI, and voltage generation during indentation - were used to characterize the $\mathrm{Sc}_{\mathrm{x}} \mathrm{Al}_{1-\mathrm{x}} \mathrm{N}$ thin films (Paper 3).

While the PNI shows a lot of promise in making the piezoelectric characterization easier, extracting the piezoelectric coefficients $e_{33}$ and $d_{33}$ has proven to be difficult due to complicated geometry and non-linear response when indenting a continuous film. However, it has been used successfully to quantify piezoelectric response in individual $\mathrm{ZnO}$ nanowires [93], where the sample deformation (nanowire elongation $\Delta l$ ) due to applied voltage $\Delta V$ is limited to one direction, and clamped piezoelectric coefficient can be expressed as follows [94]:

$$
d_{33, f}=\frac{\Delta l}{\Delta V} .
$$

\subsubsection{Other ways to determine the piezoelectric response}

Besides the PFM and PNI described above, there are many other techniques to characterize the piezoelectric materials. According to IEEE Standard on Piezoelectricity [95], none of them is considered to be the standard procedure because the choice is subject to various considerations, such as shape and size of the samples, and available instrumentation. Below, I discuss 1) principles for calculating the piezoelectric coefficient if other material properties are known, 2) double beam interferometry (DBI), 3) piezometer, and 4) other techniques.

1) If the electromechanical coupling $k_{\mathrm{T}}$, elastic coefficient $s_{33}^{E}$ and dielectric constant $\mathcal{E}_{\mathrm{r}}$ are known, the piezoelectric response $d_{33}$ (applied electric field and the resulting strain along the $c$ axis) can be calculated from the following equation:

$$
d_{33}=k_{T} \sqrt{\varepsilon_{0} \cdot \varepsilon_{r} \cdot s_{33}^{E}} .
$$


Using eq. 5.11 does not include any non-linearity that occurs in some piezoelectric materials, and it is not valid in conditions close to the resonance frequency.

In the case of a thin film "clamped" onto a stiff substrate, for example, $\mathrm{Al}_{2} \mathrm{O}_{3}$ or $\mathrm{Si}$, the piezoelectric response will be lower, and another expression is to be used to obtain the so-called clamped piezoelectric response $d_{33, f}$ :

$$
d_{33, f}=\frac{e_{33}}{c_{33}^{E}}=d_{33}-\frac{2 S_{13}}{S_{11}+S_{12}} d_{31},
$$

where $e_{33}$ is piezoelectric constant, $c_{33}^{E}$ is the elastic stiffness, and $S_{\mathrm{ij}}$ are mechanical compliance coefficients [96]. First part of eq. 5.12 was used to calculate the theoretical piezoelectric response of $\mathrm{Sc}_{\mathrm{x}} \mathrm{Al}_{1-\mathrm{x}} \mathrm{N}$ thin films in Paper 2, where values of $e_{33}$ and $c_{33}^{E}$ were taken from Ref. [34].

2) Another technique used in Paper 2 was the DBI. The main requirement from the sample preparation point of view is that both sides of the sample have to be reflective. With this requirement in mind, several structures, shown in Fig. 5.8, were deposited onto double-side polished sapphire substrates. Using this method a laser beam is split in two and guided towards the back and front sides of the sample. When an electric field is applied between the top and bottom electrodes the mechanical displacement of the film is recorded through interference between a reference beam and the beams reflected from the sample. A more detailed description of the experimental set up can be found in Ref. [97].

3) A piezometer, where a sample is clamped and subjected to low frequency force while the electrical signal is recorded, was used to characterize $\mathrm{Sc}_{\mathrm{x}} \mathrm{Al}_{1-\mathrm{x}} \mathrm{N}$ thin films by Akiyama et al. in Ref. [3]. Such piezometers are sometimes called "Berlincourt" piezometers or simply $d_{33}$-meters and were initially developed for bulk ceramic materials. Ref. [98] gives more details on the experimental set-up and suggested modifications for characterization of thin films.

4) Other techniques are available too; some of them require free-standing membranes or cantilever structures. Most of these methods were developed for 
characterizing bulk ferroelectric materials like PZT, where the piezoelectric response is reasonably stronger than in the AlN and the sample dimensions are much larger, so there can be issues with the sensitivity during the measurement, or producing thick enough samples. The main issue in piezoelectric characterization common to the techniques mentioned in this thesis is that the extracted values of piezoelectric response using different techniques are diverse even for the same sample and a direct comparison is not feasible. A discussion on this issue and a suggested solution, in the case of $\mathrm{Sc}_{\mathrm{x}} \mathrm{Al}_{1-\mathrm{x}} \mathrm{N}$, to compare values normalized to AlN are presented in Paper 2. 


\section{Chapter 6}

\section{Summary of included papers}

\section{Paper 1}

Wurtzite $\mathrm{Sc}_{\mathrm{x}} \mathrm{Al}_{1-\mathrm{x}} \mathrm{N}$ thin films with $\mathrm{x}=0.1,0.2$, and 0.3 were deposited using reactive magnetron sputter epitaxy from two elemental targets onto $\mathrm{Al}_{2} \mathrm{O}_{3}(0001)$ substrates with $\operatorname{TiN}(111)$ seed layers serving as bottom electrodes. The films were investigated from a structural and electrical point of view and compared to reference AlN samples. While the best crystalline quality of AlN was achieved at substrate temperature $\mathrm{T}_{\mathrm{s}}=800^{\circ} \mathrm{C}$, Sc-containing films deposited at the same temperature had high leakage currents and could not be used for the electrical characterization. For this reason, only ScAlN samples deposited at $400{ }^{\circ} \mathrm{C}$ were analyzed. XRD confirmed epitaxial growth for all Sc concentrations and lattice constants for $\mathrm{x}=0.1$ and 0.2 were shown to match previously published theoretical values. However, the XRD response was too low to get accurate results for $\mathrm{x}=0.3$. $\mathrm{Au} / \mathrm{Cr} / \mathrm{ScAlN} / \mathrm{TiN}$ structures were used for electrical characterization and from the capacitance $(C)$ the relative dielectric constant $\mathcal{E} r$ was extracted. These values, together with stiffness $C_{33}$ and piezoelectric constant $e_{33}$ found in literature were used to calculate the electromechanical coupling coefficient $k t^{2}$ and an increase 
from $7 \%$ for $\mathrm{AlN}$ up to $10 \%$ for $\mathrm{Sc}_{0.2} \mathrm{Al}_{0.8} \mathrm{~N}$ was obtained. High frequency dielectric constants $\mathcal{E} \|$ and $\mathcal{E} \perp$ were obtained by ellipsometry and compared to densityfunctional perturbation theory results.

\section{Paper 2}

Wurtzite $\mathrm{Sc}_{\mathrm{x}} \mathrm{Al}_{1-\mathrm{x}} \mathrm{N}$ thin films $(\mathrm{x}=0,0.1,0.2,0.3)$ were deposited using reactive magnetron sputter epitaxy from two elemental targets onto $\mathrm{Al}_{2} \mathrm{O}_{3}(0001)$ substrates with $\mathrm{TiN}(111)$ seed layers serving as bottom electrodes at $\mathrm{T}_{\mathrm{s}}=400,600$, and $800^{\circ} \mathrm{C}$. XRD and TEM together with EDX mapping were used to evaluate the microstructure and crystalline quality of the films. An increase in substrate temperature results in a degraded crystalline quality, while the microstructure of the films is more sensitive to the increase of Sc concentration. Sc-containing samples deposited at $800{ }^{\circ} \mathrm{C}$ show signs of elemental segregation into AlN-rich and $\mathrm{ScN}$-rich domains, which is more pronounced in samples with $\mathrm{x}=0.3$. Electric characterization of the films show high leakage currents in samples with $\mathrm{T}_{\mathrm{s}}>400{ }^{\circ} \mathrm{C}$ and piezoelectric characterization shows an increase in piezoelectric response by up to $180 \%$ for $\mathrm{Sc}_{0.2} \mathrm{Al}_{0.8} \mathrm{~N}$ independently of growth temperature. Normalized results match well with experimental and theoretical values found in literature.

\section{Paper 3}

Wurtzite $\mathrm{Sc}_{\mathrm{x}} \mathrm{Al}_{1-\mathrm{x}} \mathrm{N}$ thin films with $\mathrm{x}=0,0.1,0.2$, and 0.3 were deposited using reactive magnetron sputter epitaxy from two elemental targets onto $\mathrm{Al}_{2} \mathrm{O}_{3}(0001)$ substrates with $\mathrm{TiN}(111)$ seed layers serving as bottom electrodes at $\mathrm{T}_{\mathrm{s}}=400{ }^{\circ} \mathrm{C}$. Nanoindentation was used to determine the hardness and reduced elastic modulus. PFM was used to map the sample surface for domains with different piezoelectric phases. Modified $d c$ PNI and voltage generation during the nanoindentation were used to investigate the piezoelectric properties. The hardness and reduced elastic modulus decrease from $17 \mathrm{GPa}$ in $\mathrm{AlN}$ to $11 \mathrm{GPa}$ in $\mathrm{Sc}_{0.3} \mathrm{Al}_{0.7} \mathrm{~N}$, and $265 \mathrm{GPa}$ down to $224 \mathrm{GPa}$, respectively. PFM shows films to be composed of mostly one phase 
piezoelectric domain, with small inclusions of opposite polarization. A direct piezoelectric effect was observed in all investigated samples when generated voltage during the nanoindentation was measured. The voltages generated in the $\mathrm{Sc}_{\mathrm{x}} \mathrm{Al}_{1-\mathrm{x}} \mathrm{N}$ films with up to $\mathrm{x}=0.2$ were higher as compared to AlN. A converse piezoelectric effect was observed also during the PNI measurements, and the sample surface displacement was higher in $\mathrm{Sc}_{x} \mathrm{Al}_{1-\mathrm{x}} \mathrm{N}$, as compared to $\mathrm{AlN}$, scaling proportionally with $\mathrm{x}$ up to $\mathrm{x}=0.2$. A discussion about extraction of $d_{33}$ and $e_{33}$, as well as a qualitative comparison with results published in Paper 2 is included as well.

\section{Paper 4}

$\mathrm{Sc}_{\mathrm{x}} \mathrm{Al}_{1-\mathrm{x}} \mathrm{N} / \mathrm{In}_{\mathrm{y}} \mathrm{Al}_{1-\mathrm{y}} \mathrm{N}$ superlattices with $\mathrm{x}=0.2,0.3,0.4$, and $\mathrm{y}=0-0.72$ were deposited using reactive magnetron sputter epitaxy from two elemental targets onto $\mathrm{Al}_{2} \mathrm{O}_{3}(0001)$ substrates at $\mathrm{T}=500$ and $700{ }^{\circ} \mathrm{C}$. XRD, TEM, and STEM-EDX were used to evaluate the crystalline quality, the microstructure, and the elemental distribution in the superlattices. The effect of lattice mismatch on stabilization of wurtzite $\mathrm{Sc}_{\mathrm{x}} \mathrm{Al}_{1-\mathrm{x}} \mathrm{N}$ was investigated. The positive $\mathrm{Sc}_{\mathrm{x}} \mathrm{Al}_{1-\mathrm{x}} \mathrm{N}$ lattice mismatch against $\mathrm{AlN}$ has a detrimental effect on crystal structure of $\mathrm{Sc}_{\mathrm{x}} \mathrm{Al}_{1-\mathrm{x}} \mathrm{N}$ layers, while a negative lattice mismatch against $\operatorname{In}_{0.72} \mathrm{Al}_{0.28} \mathrm{~N}$ stabilizes the wurtzite $\mathrm{Sc}_{0.4} \mathrm{Al}_{0.6} \mathrm{~N}$. The experimental results are confirmed by ab initio calculations, which also indicate that epitaxial stabilization may be possible for $\mathrm{Sc}$ concentrations as high as $\mathrm{x}=0.5$.

\section{Paper 5}

$\mathrm{Y}_{\mathrm{x}} \mathrm{Al}_{1-\mathrm{x}} \mathrm{N}(\mathrm{x}=0,0.04,0.13$, and 0.22$)$ thin films were deposited using reactive magnetron sputter epitaxy from two elemental targets onto $\mathrm{Al}_{2} \mathrm{O}_{3}(0001)$ and $\mathrm{Si}(100)$ substrates. Mixing enthalpy calculations showed wurtzite to be a preferred phase up to $\mathrm{x}=0.75$, although energies for all phases are much higher than in the case of $\mathrm{Sc}_{\mathrm{x}} \mathrm{Al}_{1-\mathrm{x}} \mathrm{N}$. TEM was used for a structural analysis which showed a polycrystalline film and columnar growth. STEM and EDX mapping show no 
elemental segregation. XRD was used to measure lattice constants, comparisons with theoretical predictions show a good match indicating a solid solution. In general, the crystalline quality of the films degrades with addition of Y. Increasing the growth temperature has a positive effect on a crystalline quality of the films due to improved mobility of $\mathrm{Y}$ atoms, commonly considered as an element with a slow diffusion rate. Solid solution is confirmed by optical characterization, in which the direct band gap decreases from $6.2 \mathrm{eV}$ in pure $\mathrm{AlN}$ to $4.9 \mathrm{eV}$ in $\mathrm{Y}_{0.22} \mathrm{Al}_{0.78} \mathrm{~N}$.

\section{Paper 6}

$\mathrm{Y}_{\mathrm{x}} \mathrm{Al}_{1-\mathrm{x}} \mathrm{N}$ thin films with $\mathrm{x}=0,0.02,0.04,0.10,0.13,0.18$, and 0.22 were deposited using reactive magnetron sputter epitaxy onto $\mathrm{Si}(100)$ substrates. Spectroscopic ellipsometry was used to investigate the band gap as a function of $Y$ content $\mathrm{x}$ as well as the refractive index and the extinction coefficient. The band gap energy decreased, by a factor of $78 \mathrm{meV}$ per percent of solved $\mathrm{Y}$, from $6.2 \mathrm{eV}$ for $\mathrm{AlN}$ to $4.5 \mathrm{eV}$ for $\mathrm{Y}_{0.22} \mathrm{Al}_{0.78} \mathrm{~N}$. Improved fitting procedures were used as compared to Paper 5; this resulted in lower and more accurate band gap values for samples with high Y content. AFM was used for surface analysis. The study shows that alloying changed not only the crystalline quality but also the surface morphology of the $\mathrm{Y}_{\mathrm{x}} \mathrm{Al}_{1-\mathrm{x}} \mathrm{N}$ thin films. While the roughness was low in all samples, the grain size decreased with increasing of $\mathrm{Y}$ content. 


\section{Chapter 7}

\section{Contribution to the field}

With the research presented in this thesis I have increased the knowledge about growth of the ternary group IIIA-IIIB wurtzite nitrides $\mathrm{Sc}_{\mathrm{x}} \mathrm{Al}_{1-\mathrm{x}} \mathrm{N}$ and $\mathrm{Y}_{\mathrm{x}} \mathrm{Al}_{1}$. ${ }_{\mathrm{x}} \mathrm{N}$ and their properties:

The increase in electromechanical coupling $k_{\mathrm{t}}{ }^{2}$ upon alloying AlN with $\mathrm{ScN}$ was not reported before. I show that a decrease in growth temperature improves the quality and the dielectric properties of $\mathrm{Sc}_{\mathrm{x}} \mathrm{Al}_{1-\mathrm{x}} \mathrm{N}$ thin films. I also show that strong piezoelectric response is more likely to be present in samples with good microstructure, while the leakage currents depend more on crystalline quality. The hardness and elastic modulus of $\mathrm{Sc}_{\mathrm{x}} \mathrm{Al}_{1-\mathrm{x}} \mathrm{N}$ were not known before. Stabilization of $\mathrm{Sc}_{\mathrm{x}} \mathrm{Al}_{1-\mathrm{x}} \mathrm{N}$ in a superlattice structure with $\mathrm{In}$-rich $\mathrm{In}_{\mathrm{y}} \mathrm{Al}_{1-\mathrm{y}} \mathrm{N}$ gives some new insights into the behavior of metastable films, and the effects of lattice mismatch. I was the first one to report on $\mathrm{Y}_{\mathrm{x}} \mathrm{Al}_{1-\mathrm{x}} \mathrm{N}$ thin films, measure their lattice parameters, and to provide the band gap energy values and other optical constants with up to $\mathrm{x}=0.22$. The crystalline quality of $\mathrm{Y}_{\mathrm{x}} \mathrm{Al}_{1-\mathrm{x}} \mathrm{N}$ improved with increased growth temperature due to added ad-atom mobility needed for heavy yttrium atoms.

I believe that these findings will be helpful to someone planning a journey into the fascinating world of metastable materials. Good luck to you! 


\section{Chapter 8}

\section{Future work}

There were a lot of other ideas I wished I had time to explore during my $\mathrm{PhD}$. Here are some of them:

- Thermoelectric and pyroelectric properties of $\mathrm{Sc}_{\mathrm{x}} \mathrm{Al}_{1-\mathrm{x}} \mathrm{N}$.

- Further optimization of $\mathrm{Sc}_{\mathrm{x}} \mathrm{Al}_{1-\mathrm{x}} \mathrm{N} / \mathrm{In}_{\mathrm{y}} \mathrm{Al}_{1-\mathrm{y}} \mathrm{N}$ superlattices and their dielectric, optical, and piezoelectric properties.

- Investigation of $\mathrm{In}$-rich $\operatorname{In}_{\mathrm{y}} \mathrm{Al}_{1-\mathrm{y}} \mathrm{N}$ nanorods without core-shell structure grown by reactive magnetron sputtering, and what process parameters influence this type of growth.

- Reactive magnetron sputter epitaxy of wurtzite $\mathrm{Sc}_{\mathrm{x}} \mathrm{Ga}_{1-\mathrm{x}} \mathrm{N}$ and $\mathrm{Sc}_{\mathrm{x}} \operatorname{In}_{1-\mathrm{x}} \mathrm{N}$ thin films.

- Amorphous AlN, and whether the crystallization can be hindered by doping with small amounts of yttrium.

- $\mathrm{Y}_{\mathrm{X}} \operatorname{In}_{1-\mathrm{x}} \mathrm{N}$ could be of interest for energy harvesting applications according to $a b$ initio studies on volume matching in group IIIA-IIIB nitrides [99]. 


\section{Chapter 9}

\section{References}

[1] K.M. Lakin, A review of thin-film resonator technology, IEEE Microwave Magazine. 4 (2003) 61-67.

[2] S. Mahon, R. Aigner, "Bulk acoustic wave devices - Why, How, and Where they are going," in Proceedings of CS Mantech, 2007, pp. 15-18. [Online]. Available: http://www.csmantech.org/Digests/2007/index.htm. Last accessed: March, 2012.

[3] M. Akiyama, T. Kamohara, K. Kano, A. Teshigahara, Y. Takeuchi, N. Kawahara, Enhancement of piezoelectric response in scandium aluminum nitride alloy thin films prepared by dual reactive cosputtering, Adv Mater. 21 (2009) 593596.

[4] C. Höglund, J. Bareño, J. Birch, B. Alling, Z. Czigány, L. Hultman, Cubic $\mathrm{Sc}_{1-\mathrm{x}} \mathrm{Al}_{\mathrm{x}} \mathrm{N}$ solid solution thin films deposited by reactive magnetron sputter epitaxy onto ScN(111), J. Appl. Phys. 105 (2009) 113517.

[5] C. Höglund, J. Birch, B. Alling, J. Bareño, Z. Czigány, P.O.Å Persson, G. Wingqvist, A. Zukauskaite, L. Hultman, Wurtzite structure $\mathrm{Sc}_{1-x} \mathrm{Al}_{\mathrm{x}} \mathrm{N}$ solid solution films grown by reactive magnetron sputter epitaxy: Structural characterization and first-principles calculations, J. Appl. Phys. 107 (2010) 123515.

[6] C. Höglund, J. Birch, M. Beckers, B. Alling, Z. Czigány, A. Mücklich, L. Hultman, $\mathrm{Sc}_{3} \mathrm{AlN}$ - A new perovskite, European Journal of Inorganic Chemistry. 8 (2008) 1193-1195.

[7] C. Höglund, Growth and Phase Stability Studies of Epitaxial Sc-Al-N and Ti-Al-N Thin Films, Department of Physics, Chemistry, and Biology, Linköping University, Linköping, 2010.

[8] W.G. Cady, Piezoelectricity: An Introduction to the Theory and Applications of Electromechanical Phenomena in Crystals, 1st ed., McGraw-Hill, New York, 1946. 
[9] L.C. Lew Yan Voon, M. Willatzen, Electromechanical phenomena in semiconductor nanostructures, J. Appl. Phys. 109 (2011) 031101.

[10] B. Jaffe, W.R. Cook, H. Jaffe, Piezoelectric Ceramics, , London, 1971.

[11] J.C. Burfoot, G.W. Taylor, Polar Dielectrics and their Applications, , London, 1979.

[12] F. Bernardini, V. Fiorentini, D. Vanderbilt, Spontaneous polarization and piezoelectric constants of III-V nitrides, Physical Review B - Condensed Matter and Materials Physics. 56 (1997) R10024-R10027.

[13] S. Muensit, E.M. Goldys, I.L. Guy, Shear piezoelectric coefficients of gallium nitride and aluminum nitride, Appl. Phys. Lett. 75 (1999) 3965-3967.

[14] S. Muensit, I.L. Guy, The piezoelectric coefficient of gallium nitride thin films, Appl. Phys. Lett. 72 (1998) 1896-1898.

[15] A.F. Wright, Elastic properties of zinc-blende and wurtzite AIN, GaN, and InN, J. Appl. Phys. 82 (1997) 2833-2839.

[16] C.-. Eom, S. Trolier-McKinstry, Thin-film piezoelectric MEMS, MRS Bull. 37 (2012) 1007-1017.

[17] I. Vurgaftman, J.R. Meyer, L.R. Ram-Mohan, Band parameters for III-V compound semiconductors and their alloys, J. Appl. Phys. 89 (2001) 5815-5875.

[18] B.H. Mussler, S. Venigalla, W.C. Johnson, S. Rudolph, C. Alt, L. Burns, D. Lathrop, C. Mroz, F.P. Russo, D.A. Partis, Advanced materials \& powders, Am Ceram Soc Bull. 79 (2000) 45-56.

[19] J. Duchêne, Radiofrequency reactive sputtering for deposition of aluminium nitride thin films, Thin Solid Films. 8 (1971) 69-79.

[20] F. Bernardini, V. Fiorentini, First-principles calculation of the piezoelectric tensor d of III-V nitrides, Appl. Phys. Lett. 80 (2002) 4145-4147.

[21] C. Wood, D. Jena, Polarization Effects in Semiconductors, From Ab Initio Theory to Device Applications, (2008).

[22] M.A. Moram, M.E. Vickers, X-ray diffraction of III-nitrides, Reports on Progress in Physics. 72 (2009) 036502.

[23] M.A. Dubois, P. Muralt, Stress and piezoelectric properties of aluminum nitride thin films deposited onto metal electrodes by pulsed direct current reactive sputtering, J. Appl. Phys. 89 (2001) 6389-6395. 
[24] E. Milyutin, S. Harada, D. Martin, J.F. Carlin, N. Grandjean, V. Savu, O. Vaszquez-Mena, J. Brugger, P. Muralt, Sputtering of (001)AlN thin films: Control of polarity by a seed layer, J. Vac. Sci. Technol. B. 28 (2010) L61-L63.

[25] A. Artieda, C. Sandu, P. Muralt, Highly piezoelectric AlN thin films grown on amorphous, insulating substrates, J. Vac. Sci. Technol. A Vac. Surf. Films. 28 (2010) 390-393.

[26] J. Wright, C. Moe, A.V. Sampath, G.A. Garrett, M. Wraback, Fabrication of periodically poled AlN with sub-micron periods, Physica Status Solidi (C) Current Topics in Solid State Physics. 8 (2011) 2331-2333.

[27] P. Waltereit, O. Brandt, A. Trampert, H.T. Grahn, J. Monniger, M. Ramsteiner, M. Relche, K.H. Ploog, Nirtride semiconductors free of electrostatic fields for efficient white light-emitting diodes, Nature. 406 (2000) 865868.

[28] G. Wingqvist, Thin Film Electroacoustic Devices for Biosensor Applications, Acta Universitatis Upsaliensis, Uppsala, 2009.

[29] W. Lin, L. Meng, G. Chen, H. Liu, Epitaxial growth of cubic AlN films on (100) and (111) silicon by pulsed laser ablation, Appl. Phys. Lett. 66 (1995) 2066.

[30] A. Madan, I.W. Kim, S.C. Cheng, P. Yashar, V.P. Dravid, S.A. Barnett, Stabilization of cubic AlN in epitaxial AlN/TiN superlattices, Phys. Rev. Lett. 78 (1997) 1743-1746.

[31] N. Farrer, L. Bellaiche, Properties of hexagonal ScN versus wurtzite GaN and InN, Physical Review B - Condensed Matter and Materials Physics. 66 (2002) 2012031-2012034.

[32] D. Gall, I. Petrov, P. Desjardins, J.E. Greene, Microstructural evolution and Poisson ratio of epitaxial $\mathrm{ScN}$ grown on $\mathrm{TiN}(001) / \mathrm{MgO}(001)$ by ultrahigh vacuum reactive magnetron sputter deposition, J. Appl. Phys. 86 (1999) 5524-5529.

[33] S. Kerdsongpanya, N. Van Nong, N. Pryds, A. Žukauskaitė, J. Jensen, J. Birch, J. Lu, L. Hultman, G. Wingqvist, P. Eklund, Anomalously high thermoelectric power factor in epitaxial ScN thin films, Appl. Phys. Lett. 99 (2011) 232113.

[34] F. Tasnádi, B. Alling, C. Höglund, G. Wingqvist, J. Birch, L. Hultman, I.A. Abrikosov, Origin of the anomalous piezoelectric response in wurtzite $\mathrm{Sc}_{\mathrm{x}} \mathrm{Al}_{1-\mathrm{x}} \mathrm{N}$ alloys, Phys. Rev. Lett. 104 (2010) 137601.

[35] R. Matloub, A. Artieda, C. Sandu, E. Milyutin, P. Muralt, Electromechanical properties of $\mathrm{Al}_{0.9} \mathrm{Sc}_{0.1} \mathrm{~N}$ thin films evaluated at $2.5 \mathrm{GHz}$ film bulk acoustic resonators, Appl. Phys. Lett. 99 (2011) 092903. 
[36] M. Moreira, J. Bjurström, I. Katardjev, V. Yantchev, Aluminum scandium nitride thin-film bulk acoustic resonators for wide band applications, Vacuum. 86 (2011) 23-26.

[37] M.A. Moreira, J. Bjurström, V. Yantchev, I. Katardjiev, Synthesis and characterization of highly c-textured $\mathrm{Al}_{1-\mathrm{x}} \mathrm{Sc}_{\mathrm{x}} \mathrm{N}$ thin films in view of telecom applications, IOP Conf. Ser. Mater. Sci. Eng. 41 (2012).

[38] R. Matloub, M. Hadad, A. Mazzalai, N. Chidambaram, G. Moulard, C.S. Sandu, T. Metzger, P. Muralt, Piezoelectric $\mathrm{Al}_{1-x} \mathrm{Sc}_{\mathrm{x}} \mathrm{N}$ thin films: A semiconductor compatible solution for mechanical energy harvesting and sensors, Appl. Phys. Lett. 102 (2013).

[39] K.-. Hashimoto, S. Sato, A. Teshigahara, T. Nakamura, K. Kano, Highperformance surface acoustic wave resonators in the 1 to $3 \mathrm{GHz}$ range using a ScAlN/6H-SiC structure, IEEE Trans. Ultrason. Ferroelectr. Freq. Control. 60 (2013) 637-642.

[40] Q. Guo, O. Kato, A. Yoshida, Thermal stability of indium nitride single crystal films, J. Appl. Phys. 73 (1993) 7969-7971.

[41] H. Morkoç, Handbook of Nitride Semiconductors and Devices, (2009) 1323.

[42] J. Palisaitis, C.-. Hsiao, L. Hultman, J. Birch, P.O.Å Persson, Thermal stability of $\mathrm{Al}_{1-\mathrm{x}} \mathrm{In}_{\mathrm{x}} \mathrm{N}\left(\begin{array}{llll}0 & 0 & 0 & 1\end{array}\right)$ throughout the compositional range as investigated during in situ thermal annealing in a scanning transmission electron microscope, Acta Mater. 61 (2013) 4683-4688.

[43] M. Birkholz, Thin Film Analysis by X-Ray Scattering, Wiley-VCH, Weinheim, 2006.

[44] C.L. Hsiao, J. Palisaitis, M. Junaid, P.O.Å Persson, J. Jensen, Q.-. Zhao, L. Hultman, L.-. Chen, K.-. Chen, J. Birch, Room-temperature heteroepitaxy of single-phase $\mathrm{Al}_{1-\mathrm{x}} \mathrm{In}_{\mathrm{x}} \mathrm{N}$ films with full composition range on isostructural wurtzite templates, Thin Solid Films. 524 (2012) 113-120.

[45] J.M. Gregoire, S.D. Kirby, G.E. Scopelianos, F.H. Lee, R.B. Van Dover, High mobility single crystalline $\mathrm{ScN}$ and single-orientation epitaxial $\mathrm{YN}$ on sapphire via magnetron sputtering, J. Appl. Phys. 104 (2008) 074913.

[46] J.P. Dismukes, W.M. Yim, J.J. Tietjen, R.E. Novak, Vapor deposition of semiconducting mononitrides of scandium, yttrium, and the rare- earth elements, R.C.A.Review. 31 (1970) 680-691.

[47] J.M. Gregoire, S.D. Kirby, M.E. Turk, R.B. van Dover, Structural, electronic and optical properties of (Sc,Y)N solid solutions, Thin Solid Films. 517 (2009) 1607-1609. 
[48] C.N. Zoita, M. Braic, V. Braic, Structural, optical and electronic properties of $\mathrm{In}_{1-\mathrm{x}} \mathrm{Y}_{\mathrm{x}} \mathrm{N}$ thin films, Dig. J. Nanomat. Biostr. 6 (2011) 1877-1886.

[49] C. Stampfl, W. Mannstadt, R. Asahi, A.J. Freeman, Electronic structure and physical properties of early transition metal mononitrides: Density-functional theory LDA, GGA, and screened-exchange LDA FLAPW calculations, Phys. Rev. B Condens. Matter Mater. Phys. 63 (2001) 1551061-15510611.

[50] T. Lü, M. Huang, Electronic structure of ScN and YN: Density-functional theory LDA and GW approximation calculations, Chin. Phys. 16 (2007) 62-66.

[51] W. De La Cruz, J.A. D́az, L. Mancera, N. Takeuchi, G. Soto, Yttrium nitride thin films grown by reactive laser ablation, J Phys Chem Solids. 64 (2003) 22732279.

[52] F. Rovere, P.H. Mayrhofer, Impact of yttrium on structure and mechanical properties of Cr-Al-N thin films, J. Vac. Sci. Technol. A Vac. Surf. Films. 25 (2007) 1336- 1340.

[53] F. Rovere, D. Music, J.M. Schneider, P.H. Mayrhofer, Experimental and computational study on the effect of yttrium on the phase stability of sputtered $\mathrm{Cr}-\mathrm{Al}-\mathrm{Y}-\mathrm{N}$ hard coatings, Acta Materialia. 58 (2010) 2708-2715.

[54] M.I. Lembke, D.B. Lewis, W.D. Münz, J.M. Titchmarsh, Significance of Y and Cr in TiAlN hard coatings for dry high speed cutting, Surf Eng. 17 (2001) 153-158.

[55] W. Lei, D. Liu, X. Chen, P. Zhu, Q. Cui, G. Zou, Ferromagnetic properties of Ydoped AlN nanorods, J. Phys. Chem. C. 114 (2010) 15574-15577.

[56] J.C. Schuster, J. Bauer, The ternary systems ScAlN and YAlN, Journal of The Less-Common Metals. 109 (1985) 345-350.

[57] M. Ohring, Elsevier Science Publishers, Materials Science of Thin Films, 2nd ed., Academic Press, San Diego, CA, 2002.

[58] Historical Timeline of Vacuum Coating and Vacuum/Plasma Technology, http://www.svc.org/HistoryofVacuumCoating/History-of-Vacuum-Coating.cfm, Last accessed: March, 2012.

[59] D.W. Hoffman, J.A. Thornton, Internal Stresses in Cr, Mo, Ta, and Pt Films Deposited by Sputtering from a Planar Magnetron Source, J. Vac. Sci. Technol. 20 (1981) 355-358.

[60] H.F. Winters, E. Kay, Gas incorporation into sputtered films, J. Appl. Phys. 38 (1967) 3928-3934. 
[61] V. Stambouli, O. Burat, D. Bouchier, F. Meyer, J. Gilles, G. Gautherin, Argon incorporation effects on the conductivity of metal layers, Thin Solid Films. 193-194 (1990) 181-188.

[62] K.H. Kim, C.H. Chang, Y.M. Koo, Structural characterization of AlN thin film deposited on a single crystal of Al2O3(0001) substrate, Mater Lett. 34 (1998) 19-22.

[63] M. Akiyama, T. Kamohara, K. Kano, A. Teshigahara, N. Kawahara, Influence of oxygen concentration in sputtering gas on piezoelectric response of aluminum nitride thin films, Appl. Phys. Lett. 93 (2008) 021903.

[64] G.F. Iriarte, Influence of the magnetron on the growth of aluminum nitride thin films deposited by reactive sputtering, J. Vac. Sci. Technol. A Vac. Surf. Films. 28 (2010) 193-198.

[65] W.J. Meng, J.A. Sell, T.A. Perry, L.E. Rehn, P.M. Baldo, Growth of aluminum nitride thin films on $\mathrm{Si}(111)$ and $\mathrm{Si}(001)$ : Structural characteristics and development of intrinsic stresses, J. Appl. Phys. 75 (1994) 3446-3455.

[66] T. Seppänen, Growth and Characterization of Metastable Wide Band-Gap $\mathrm{Al}_{1-\mathrm{X}} \mathrm{In}_{\mathrm{x}} \mathrm{N}$ Epilayers, Department of Physics, Chemistry, and Biology, Linköping University, Linköping, 2006.

[67] T. Seppänen, P.O.Å Persson, L. Hultman, J. Birch, G.Z. Radnóczi, Magnetron sputter epitaxy of wurtzite $\mathrm{Al}_{1-\mathrm{x}} \operatorname{In}_{\mathrm{x}} \mathrm{N}(0.1<\mathrm{x}<0.9)$ by dual reactive dc magnetron sputter deposition, J Appl Phys. 97 (2005).

[68] T. Seppänen, L. Hultman, J. Birch, $248 \mathrm{~nm}$ cathodoluminescence in $\mathrm{Al}_{1-\mathrm{x}} \mathrm{In}_{\mathrm{x}} \mathrm{N}$ (0001) thin films grown on lattice-matched $\mathrm{Ti}_{1-\mathrm{y}} \mathrm{Zr}_{\mathrm{y}} \mathrm{N}$ (111) seed layers by low temperature magnetron sputter epitaxy, Appl Phys Lett. 89 (2006).

[69] H. Koeppe, Dissertation, Universitat Giessen (1923),.

[70] W. Deubner, Versuche über die Reflexion von Röntgenstrahlen an einem künstlich hergestellten Schichtenkörper. (Mit 5 Figuren), Annalen der Physik. 397 (1930) 261-280.

[71] L. Esaki, R. Tsu, Superlattice and negative differential conductivity in semiconductors, IBM J. Res. Dev. 14. (1970) 61.

[72] W. Kohn, L.J. Sham, Self-consistent equations including exchange and correlation effects, Physical Review. 140 (1965) A1133-A1138.

[73] G. Kresse, J. Furthmüller, Efficient iterative schemes for ab initio totalenergy calculations using a plane-wave basis set, Phys. Rev. B Condens. Matter Mater. Phys. 54 (1996) 11169-11186. 
[74] G. Kresse, J. Furthmüller, Efficiency of ab-initio total energy calculations for metals and semiconductors using a plane-wave basis set, Computational Materials Science. 6 (1996) 15-50.

[75] P.E. Blöchl, Projector augmented-wave method, Physical Review B. 50 (1994) 17953-17979.

[76] J.P. Perdew, K. Burke, M. Ernzerhof, Generalized gradient approximation made simple, Phys. Rev. Lett. 77 (1996) 3865-3868.

[77] A. Zunger, S.-. Wei, L.G. Ferreira, J.E. Bernard, Special quasirandom structures, Phys. Rev. Lett. 65 (1990) 353-356.

[78] C. Höglund, B. Alling, J. Birch, M. Beckers, P.O.Å Persson, C. Baehtz, Z. Czigány, J. Jensen, L. Hultman, Effects of volume mismatch and electronic structure on the decomposition of ScAlN and TiAlN solid solutions, Phys. Rev. B Condens. Matter Mater. Phys. 81 (2010) 224101.

[79] S. Zhang, W.Y. Fu, D. Holec, C.J. Humphreys, M.A. Moram, Elastic constants and critical thicknesses of ScGaN and ScAlN, J. Appl. Phys. 114 (2013).

[80] E. Chason, T.M. Mayer, Thin film and surface characterization by specular Xray reflectivity, Critical Reviews in Solid State and Materials Sciences. 22 (1997) $1-67$.

[81] D.B. Williams, C.B. Carter, Transmission Electron Microscopy: A Textbook for Materials Science, Plenum Press, New York, 1996.

[82] R. Howland, L. Benatar, A Practical Guide to Scanning Probe Microscopy, Park Scientific Instruments, CA, 2000.

[83] A.C. Fischer-Cripps, SpringerLink, Nanoindentation, 1 (2011).

[84] K.D. Sattler, Handbook of nanophysics, 5 (2010) 816.

[85] H. Bubert, H. Jenett, Surface and Thin Film Analysis, Wiley-VCH, Weinheim, 2002.

[86] H. Fujiwara, Spectroscopic Ellipsometry: Principles and Applications, John Wiley \& Sons, Chichester, England ; Hoboken, NJ, 2007.

[87] N.B. Sedrine, A. Žukauskaitè, J. Birch, J. Jensen, L. Hultman, S. Schoeche, M. Schubert, V. Darakchieva, Optical phonons and infrared dielectric functions of wurtzite $\mathrm{Y}_{\mathrm{x}} \mathrm{Al}_{1-\mathrm{x}} \mathrm{N}$, In manuscript. (2014).

[88] A. Gruverman, S.V. Kalinin, Piezoresponse force microscopy and recent advances in nanoscale studies of ferroelectrics, J. Mater. Sci. 41 (2006) 107-116. 
[89] E. Soergel, Piezoresponse force microscopy (PFM), J. Phys. D. 44 (2011) 464003.

[90] A. Rar, G.M. Pharr, W.C. Oliver, E. Karapetian, S.V. Kalinin, Piezoelectric nanoindentation, J. Mater. Res. 21 (2006) 552-556.

[91] M. Bhaskaran, S. Sriram, S. Ruffell, A. Mitchell, Nanoscale characterization of energy generation from piezoelectric thin films, Advanced Functional Materials. 21 (2011) 2251-2257.

[92] S. Sridhar, A.E. Giannakopoulos, S. Suresh, U. Ramamurty, Electrical response during indentation of piezoelectric materials: A new method for material characterization, J. Appl. Phys. 85 (1999) 380-387.

[93] E. Broitman, M.Y. Soomro, J. Lu, M. Willander, L. Hultman, Nanoscale piezoelectric response of $\mathrm{ZnO}$ nanowires measured using a nanoindentation technique, Phys. Chem. Chem. Phys. 15 (2013) 11113-11118.

[94] H.D. Espinosa, R.A. Bernal, M. Minary-Jolandan, A Review of Mechanical and Electromechanical Properties of Piezoelectric Nanowires, Adv Mater. 24 (2012) 4656- 4675 .

[95] IEEE Standard on Piezoelectricity, ANSI/IEEE Std 176-1987. (1988).

[96] O. Ambacher, M. Eickhoff, A. Link, M. Hermann, M. Stutzmann, F. Bernardini, V. Fiorentini, Y. Smorchkova, J. Speck, U. Mishra, W. Schaff, V. Tilak, L.F. Eastman, Electronics and sensors based on pyroelectric AlGaN/GaN heterostructures, physica status solidi (c). 0 (2003) 1878-1907.

[97] A.L. Kholkin, C. Wütchrich, D.V. Taylor, N. Setter, Interferometric measurements of electric field-induced displacements in piezoelectric thin films, Rev. Sci. Instrum. 67 (1996) 1935-1941.

[98] J.E.A. Southin, S.A. Wilson, D. Schmitt, R.W. Whatmore, e es1,f determination for PZT films using a conventional ' $\mathrm{d}_{33}$ ' meter, J. Phys. D. 34 (2001) 1456-1460.

[99] C. Tholander, I.A. Abrikosov, L. Hultman, F. Tasnádi, Volume matching condition to establish the enhanced piezoelectricity in ternary $(\mathrm{Sc}, \mathrm{Y})_{0.5}(\mathrm{Al}, \mathrm{Ga}, \mathrm{In})_{0.5} \mathrm{~N}$ alloys, Phys. Rev. B Condens. Matter Mater. Phys. 87 (2013). 


\section{Included Papers}

The articles associated with this thesis have been removed for copyright reasons. For more details about these see:

http://urn.kb.se/resolve?urn=urn:nbn:se:liu:diva-103832 